\title{
The ferrite/oxide interface and helium management in nano-structured ferritic alloys from the first principles
}

\author{
Litong Yang ${ }^{1,2}$, Yong Jiang ${ }^{1,2,3 *}$, Yuan $\mathrm{Wu}^{4}$, G. Robert Odette ${ }^{4 *}$, Zhangjian Zhou ${ }^{5}$ Zheng Lu$^{6}$ \\ ${ }^{1}$ School of Materials Science and Engineering, and ${ }^{2}$ Key Lab of Nonferrous Materials of Ministry of \\ Education, Central South University, Changsha, 410083, China \\ ${ }^{3}$ National Key Lab for Powder Metallurgy, Central South University, Changsha 410083, China \\ ${ }^{4}$ Materials Department, University of California, Santa Barbara, 93106, USA \\ ${ }^{5}$ School of Materials Science and Engineering, University of Science and Technology, Beijing, 100083, \\ China \\ ${ }^{6}$ School of Materials and Metallurgy, Northeastern University, Shenyang, 110819, China
}

\begin{abstract}
Nano-size Y-Ti-oxides are largely responsible for the extraordinary mechanical properties and irradiation tolerance of nano-structured ferritic alloys (NFAs). Here we report a theoretical study to assess the characters and possible roles of the ferrite/oxide interface in managing neutron transmutation product helium in NFAs. Using one observed cube-on-cube orientation relationship, various candidate structures of the ferrite $/ \mathrm{Y}_{2} \mathrm{Ti}_{2} \mathrm{O}_{7}$ interfaces were constructed and the associated energies were carefully evaluated. The interface phase diagram is obtained by expressing the energy as a function of temperature and internal oxygen activity (expressed in terms of oxygen partial pressure). The oxide interfaces are predicted to be Y/Ti-rich at thermodynamic equilibrium for the wide temperature range of interest. Vacancy formation energies are lower and helium segregates to the interfaces, in preference to the iron matrix and grain boundaries. Combined with our previous results on bulk-phase $\mathrm{Y}_{2} \mathrm{Ti}_{2} \mathrm{O}_{7}$, the profound implications of nano-oxides to helium management in NFAs are discussed.
\end{abstract}

\section{Keywords}

Nano-structured ferritic alloys; $\mathrm{Y}_{2} \mathrm{Ti}_{2} \mathrm{O}_{7}$; interface; helium; density functional theory

* Corresponding authors.

E-mail address: yjiang@csu.edu.cn (Y. Jiang); odette@engineering.ucsb.edu (G. Robert Odette) 


\section{Introduction}

Nano-structured ferritic alloys (NFAs) are characterized by fine grains and an ultra-high density of Y/Ti-enriched nano-oxides [1-5], representing a new class of potentially transformational structural materials, especially for advanced fission and fusion energy applications [6-10]. The nano-oxides, which precipitate from the matrix during hot consolidation, are remarkably stable both at high temperatures and after large neutron irradiation doses. They can effectively impede dislocation climb and glide, and they enhance vacancy-SIA (self-interstitial atom) recombination; thus, they are responsible for the high tensile, creep, and fatigue strength, as well as the irradiation tolerance of NFAs [6, 11-21]. Most notably, the high density of nano-oxides results in a greatly reduced size of helium bubbles in the ferrite matrix and lower amount of helium reaching grain boundaries. Consequently, many manifestations of damaging irradiation effects, such as void swelling and helium embrittlement, are greatly mitigated in NFAs $[6,11,12]$. However, a comprehensive understanding of the mechanism responsible for the multi-functional role of nano-oxides is not yet in hand.

Various studies have suggested that the nano-oxides might range from coherent solute-enriched clusters or Guinier-Preston-type zones, to near-stoichiometric complex oxides, that are primarily the pyrochlore $\mathrm{Y}_{2} \mathrm{Ti}_{2} \mathrm{O}_{7}$ and to a lesser extent orthorhombic $\mathrm{Y}_{2} \mathrm{TiO}_{5}$ (and/or even less some other possible oxides in crystalline and even amorphous phases) [16, 22-31]. In our previous work [32, 33], we have shown from first principles that helium in NFAs partitions and is deeply trapped in both $\mathrm{Y}_{2} \mathrm{Ti}_{2} \mathrm{O}_{7}$ and $\mathrm{Y}_{2} \mathrm{TiO}_{5}$ oxides. The Boltzmann partitioning factors at $773 \mathrm{~K}$ were estimated to be in the order of $\sim 10^{10}$ and $10^{8}$ for bulk $\mathrm{Y}_{2} \mathrm{TiO}_{5}$ and $\mathrm{Y}_{2} \mathrm{Ti}_{2} \mathrm{O}_{7}$, respectively. Thus even small volume fractions of nano-oxides can effectively sequester hundreds to thousands appm of helium generated in fusion neutron environments, depending on their number density. Specifically, dispersing helium atoms into a large number of small oxides limits the helium bubble size in matrix and the corresponding damage 
potential.

While the previous results shed useful insights on helium management by the nano-oxides in NFAs, one may still ask if the interfaces of the oxides could be equally - if not more - critical by directly forming oxide-associated bubbles. In either case, it is important to determine the energies of helium in all potential residence sites. Besides helium issues, the oxide interfaces play a dominant role in many other aspects of NFA processing and service functionality, ranging from interactions with dislocations and boundaries to oxide nucleation, growth, and coarsening kinetics. Therefore, understanding the ferrite/oxide interface structures, energies, and their interaction with various microstructural and defect features, such as helium, is one of the key requirements for optimizing NFAs and achieving a correspondingly comprehensive understanding of helium fate and consequences.

In the present work, we focus on the $\mathrm{Y}_{2} \mathrm{Ti}_{2} \mathrm{O}_{7}$ interfaces with the matrix. The pyrochlore $\mathrm{Y}_{2} \mathrm{Ti}_{2} \mathrm{O}_{7}$ is generally observed to be the primary nano-oxide precipitate phase in NFAs [13]. Different orientation relationships (ORs) of ferrite $/ \mathrm{Y}_{2} \mathrm{Ti}_{2} \mathrm{O}_{7}$ have been observed. Ribis et al. reported a cube-on-cube OR for thermally-coarsened $\mathrm{Y}_{2} \mathrm{Ti}_{2} \mathrm{O}_{7}$ as $\{100\}<100>_{\text {ferrite }} / /\{100\}<100>_{\mathrm{Y} 2 \mathrm{Ti2} 27}[34]$. Using state-of-the-art aberration-corrected TEM, Ciston et al [35] observed two other types of ORs for small $\mathrm{Y}_{2} \mathrm{Ti}_{2} \mathrm{O}_{7}$ nano-oxides, i.e. the Baker-Nutting $\mathrm{OR}$ of $\{100\}<100>_{\text {ferrite }} /\{100\}<110>_{\mathrm{Y} 2 \mathrm{Ti} 2 \mathrm{O} 7}$ and a

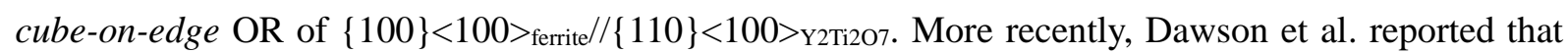
the cube-on-cube OR is more prevalent than the Baker-Nutting OR [36]. It is also worth noting that we recently developed a mesoscopic ferrite $/ \mathrm{Y}_{2} \mathrm{Ti}_{2} \mathrm{O}_{7}$ interface by directly electron-beam depositing $\mathrm{Fe}$ onto different facets of single-crystal $\mathrm{Y}_{2} \mathrm{Ti}_{2} \mathrm{O}_{7}$. High-resolution TEM, X-ray diffraction, and electron backscattering diffraction (EBSD) characterization showed two ORs of $\{110\}\langle 100\rangle_{\text {ferrite }}$ $/ /\{111\}<110>_{\mathrm{Y} 2 \mathrm{Ti2O}}$ and $\{100\}<100>_{\text {ferrite }} / /\{111\}<110>_{\mathrm{Y} 2 \mathrm{Ti} 2 \mathrm{O} 7}$ for $\mathrm{Y}_{2} \mathrm{Ti}_{2} \mathrm{O}_{7}\{111\}[37]$, the Pitsch $\mathrm{OR}$ of 
$\left.\{110\}<111\rangle_{\text {ferrite }} / /\{100\}<110\right\rangle_{\mathrm{Y} 2 \mathrm{Ti} 2 \mathrm{O} 7}$ for $\mathrm{Y}_{2} \mathrm{Ti}_{2} \mathrm{O}_{7}\{100\}$, and the cube-on-edge $\mathrm{OR}$ of $\{100\}\langle 100\rangle_{\text {ferrite }}$ $/ /\{110\}<100>_{\mathrm{Y} 2 \mathrm{Ti} 2 \mathrm{O} 7}$ for $\mathrm{Y}_{2} \mathrm{Ti}_{2} \mathrm{O}_{7}\{110\}$ surfaces.

By reviewing all these experimental characterization results, we decided to focus on the more prevalent cube-on-cube $\mathrm{OR}$ of the ferrite $/ \mathrm{Y}_{2} \mathrm{Ti}_{2} \mathrm{O}_{7}$ interfaces, i.e. $\{100\}\langle 100\rangle_{\text {ferrite }} / /\{100\}\langle 100\rangle_{\mathrm{Y} 2 \mathrm{Ti} 207}$ $[34,36]$. We first calculated the interface configurations and the associated energies with all possible stoichiometric and coordination types, as a function of temperature $(T)$ and oxygen partial pressure $\left(p_{\mathrm{O} 2}\right)$. The interface phase diagram was constructed to determine the most energy-favorable interface structures and termination chemistries for a wide temperature range of interest. Further calculations were performed to compare various helium trapping sites at both perfect and vacancy-containing interfaces. The results were then carefully compared with those previously obtained for bulk $\mathrm{Y}_{2} \mathrm{Ti}_{2} \mathrm{O}_{7}$ and in the ferrite matrix, to assess the nano-oxide interface role in trapping helium and forming associated helium bubbles. This provides a foundation for proposing a modified mechanism for helium transport and fate in NFAs.

\section{Calculation methods}

All structural relaxations and energetic calculations were performed using the density functional theory (DFT) code - VASP (Vienna Ab-initio Simulation Package) [38], with the plane-wave basis sets. The electron-core interaction was described by the Blöchl projector augmented wave method (PAW) within the frozen-core approximation [39] as implemented in VASP. The plane-wave basis sets were generated with valence configurations of He-1s2, Fe- $3 d^{6} 4 s^{2}, Y-4 s^{2} 4 p^{6} 4 d^{1} 5 s^{2}$, Ti- $-3 s^{2} 3 p^{6} 3 d^{2} 4 s^{2}$, and $\mathrm{O}-2 \mathrm{~s}^{2} 2 \mathrm{p}^{4}$. Validation of the exchange-correlation (XC) functional was performed by fitting the energy-volume relation for bcc $\mathrm{Fe}$ and pyrochlore $\mathrm{Y}_{2} \mathrm{Ti}_{2} \mathrm{O}_{7}$ to the universal equation of state [40]. The tested XC-functionals included local-density approximation (LDA) [41], and the generalized gradient 
approximation (GGA) with the Perdew-Wang-91 functional (PW91) [42] and the Perdew-BurkeErnzerhof (PBE) functional [43]. The PAW-PW91 functionals were finally chosen for all subsequent calculations, since they yielded the best prediction of bulk bcc $\mathrm{Fe}(a=2.8303 \AA$, bulk modulus $B=174 \mathrm{GPa})$ and pyrochlore $\mathrm{Y}_{2} \mathrm{Ti}_{2} \mathrm{O}_{7}(a=10.1835 \AA, B=183 \mathrm{GPa})$, compared to experiments and other calculations [44-52].

To model the interfaces, we used a ferrite/oxide/ferrite sandwich supercell with a vacuum thickness of at least $12 \AA$ and with a $2 \times 2 \times 1$ Monkhorst-Pack $k$-mesh. The electronic relaxation algorithm employed the residual minimization scheme - direct inversion in the iterative subspace (RMM-DIIS). All ground-state configurations were optimized using a high energy-cutoff of $500 \mathrm{eV}$ for the plane-wave basis sets. For all the interface structures considered, the calculations allowed for full relaxation by varying atomic configurations in space to minimize the Hellman-Feyman forces (using a combined blocked Davidson + RMM-DIIS algorithm) until the total forces on each ion were converged to within $0.02 \mathrm{eV} / \mathrm{A}$.

\section{Results and discussion}

\subsection{Interface structures}

It is not practical to have an arbitrarily large unit cell with misfit dislocations included naturally, so we chose to strain the $\mathrm{Fe}(100)$ and the $\mathrm{Y}_{2} \mathrm{Ti}_{2} \mathrm{O}_{7}(100)$ surfaces into commensuration in a manner consistent with the Ribis' cube-on-cube OR. The resulting interface structure of $\mathrm{Fe}(100)(2 \sqrt{2} \times 2 \sqrt{2})$ $/ \mathrm{Y}_{2} \mathrm{Ti}_{2} \mathrm{O}_{7}(100)(\sqrt{2} / 2 \times \sqrt{2} / 2)$ is shown in Fig. 1. In this sandwich supercell of $\mathrm{Fe} / \mathrm{Y}_{2} \mathrm{Ti}_{2} \mathrm{O}_{7} / \mathrm{Fe}$, each Fe block contains five atomic layers with a total of forty $\mathrm{Fe}$ atoms and the oxide block consists of a conventional unit cell of $\mathrm{Y}_{2} \mathrm{Ti}_{2} \mathrm{O}_{7}$. This supercell has the lowest strains to commensuration: the $\mathrm{Fe}$ lattice is compressed by $5.1 \%$ and the $\mathrm{Y}_{2} \mathrm{Ti}_{2} \mathrm{O}_{7}$ lattice is stretched by $5.4 \%$ along 
$\left.\langle 100\rangle_{\mathrm{Fe}}(/ /<100\rangle_{\mathrm{Y} 2 \mathrm{Ti} 207}\right)$, leading to a perfect matching of $4 \mathrm{~d}\{110\}_{\mathrm{Fe}}$ with $4 \mathrm{~d}\{440\}_{\mathrm{Y} 2 \mathrm{Ti} 207}$. The associated commensuration strain is slightly larger than, yet as close as possible to, that deduced from Ribis' observations (where every $8 \mathrm{~d}\{110\}_{\mathrm{Fe}}$ matches $9 \mathrm{~d}\{440\}_{\mathrm{Y} 2 \mathrm{Ti2}} \mathrm{O7}$ perfectly [34]). The strain effect shall be regarded as highly localized, only within a few atomic layers from the interface plane (as modeled in Fig. 1), since misfit dislocations can effectively relax the strains - more in deeper layers.

Given the OR and the interfacial strains, the stability of an interface structure is dictated by interfacial stoichiometry and interfacial coordination [53, 54]. According to our previous study [55], a polar free surface of $\mathrm{Y}_{2} \mathrm{Ti}_{2} \mathrm{O}_{7}$ may have various possible chemical terminations, or stoichiometry, depending on the oxygen activity (expressed in term of oxygen partial pressure). Similarly, depending on the internal local oxygen activity, one of three typical stoichiometry types is selected on the oxide side of the ferrite $/ \mathrm{Y}_{2} \mathrm{Ti}_{2} \mathrm{O}_{7}$ interface, namely the stoichiometric (labeled as stoi), the non-stoichiometric Y/Ti-rich (ns-2Y2Ti), and the non-stoichiometric O-rich type (ns-5O). For each stoichiometry type, we further considered at least two different coordination types (shown in Fig. 1), by translating the metal relative to $\mathrm{Y}_{2} \mathrm{Ti}_{2} \mathrm{O}_{7}$, i.e. placing the $\mathrm{Fe}$ atoms right above the $\mathrm{Y}$ and Ti atoms ("top-coordinated"), or at the bridge sites of the $\mathrm{Y}$ and Ti atoms ("bridge-coordinated"). The latter configuration may also be seen as the O-top coordination. The interface coordination type and stoichiometry dictate the local chemical environment at interface, which in turn dictates the interface structure and properties, such as formation energy, relative stability, adhesion strength, and segregation effects. Note, these effects have been studied for other metal/oxide systems including $\mathrm{Ni} / \mathrm{Al}_{2} \mathrm{O}_{3}$ and $\mathrm{Cu} / \mathrm{Al}_{2} \mathrm{O}_{3}$ [53, 54, 56-58]. Calculations of the resulting interface ensembles suggested that the bridge-coordinated interfaces, either Y/Ti-rich or stoichiometric, always have lower formation energies than their top-coordinated counterparts. The top-coordinated, O-rich interface is particularly unstable: it transforms immediately into a bridge-coordinated configuration during the full relaxation of the structure. Thus all the 
following calculations and discussion are restricted to the bridge-coordinated interfaces that, again, can be either Y/Ti-rich, stoichiometric, or O-rich.

Fig. 1 The sandwich supercell for the $\mathrm{Fe}(100)(2 \sqrt{2} \times 2 \sqrt{2}) / \mathrm{Y}_{2} \mathrm{Ti}_{2} \mathrm{O}_{7}(100)(\sqrt{2} / 2 \times \sqrt{2} / 2)$ interface and the two representative coordination types: (a) Y/Ti-top and (b) Y/Ti-bridge. For clarity, we only show the interfacial atoms of Fe, Y, and Ti in top-views.

\subsection{Oxygen chemical activity and interface phase diagram}

NFAs are typically processed by mechanically alloying Fe-based pre-alloyed powders ( $\mathrm{Fe}, \mathrm{Ti}, \mathrm{Cr})$ with $\mathrm{Y}_{2} \mathrm{O}_{3}$ oxide powders by high-energy ball milling. The $\mathrm{Y}_{2} \mathrm{O}_{3}$ constituents are mechanically forced into solution (dissolved) by ball milling, and then precipitate with Ti from the matrix during the subsequent hot consolidation $[1,15,59]$. We chose to represent the equilibrated chemical reaction as

$$
\mathrm{Y}_{2} \mathrm{O}_{3}+2 \mathrm{Ti}+2 \mathrm{O}_{2} \rightarrow \mathrm{Y}_{2} \mathrm{Ti}_{2} \mathrm{O}_{7}
$$

To determine the appropriate interface structure under a given thermodynamic equilibrium condition, we employed a defect thermodynamic model for interface energy $\left(\gamma_{\mathrm{I}}\right)$ in accordance with Eq. (1), as

$$
\begin{aligned}
\gamma_{\mathrm{I}} & =\frac{1}{2 A}\left(G_{0}-N_{\mathrm{Fe}} \mu_{\mathrm{Fe}}-N_{\mathrm{Y}_{2} \mathrm{O}_{3}} \mu_{\mathrm{Y}_{2} \mathrm{O}_{3}}-N_{\mathrm{Ti}} \mu_{\mathrm{Ti}}-N_{\mathrm{O}_{2}} \mu_{\mathrm{O}_{2}}\right) \\
& =\frac{1}{2 A}\left[G_{0}-N_{\mathrm{Fe}} \mu_{\mathrm{Fe}}^{0}-\frac{1}{2} N_{\mathrm{Ti}_{1}} \mu_{\mathrm{Y}_{2} \mathrm{Ti}_{2} \mathrm{O}_{7}}^{0}+\left(\frac{1}{2} N_{\mathrm{Ti}}-N_{\mathrm{Y}_{2} \mathrm{O}_{3}}\right) \mu_{\mathrm{Y}_{2} \mathrm{O}_{3}}^{0}+\frac{1}{2}\left(2 N_{\mathrm{Ti}_{1}}+3 N_{\mathrm{Y}_{2} \mathrm{O}_{3}}-N_{\mathrm{O}}\right)\left(\mu_{\mathrm{O}_{2}}^{0}+k T \ln p_{\mathrm{O}_{2}}\right)\right]
\end{aligned}
$$

Here $G_{0}$ is the Gibbs free energy of the interface ensemble, while $N_{\mathrm{i}}$ and $\mu_{\mathrm{i}}$ are, respectively, the number and chemical potential of each species $i\left(i=\mathrm{Fe}, \mathrm{O}, \mathrm{Y}, \mathrm{Ti}, \mathrm{Y}_{2} \mathrm{Ti}_{2} \mathrm{O}_{7}\right.$, or $\left.\mathrm{Y}_{2} \mathrm{O}_{3}\right)$. The superscript " 0 " refers to the pure bulk state of each species, and $A$ is the cross-sectional area of the interface. $p_{\mathrm{O} 2}$ refers to the oxygen partial pressure that reflects the local oxygen activity near the interface, and $T$ is the temperature. Note, if we assume that a fixed Y:Ti ratio holds in all these interface ensembles, i.e. 


$$
\begin{aligned}
& N_{\mathrm{Y}}=N_{\mathrm{Ti}} \text {, or } N_{\mathrm{Y}_{2} \mathrm{O}_{3}}=\frac{1}{2} N_{\mathrm{Ti}} \text { [55], we can rewrite Eq. (2) as } \\
& \gamma_{\mathrm{I}}=\frac{1}{2 A}\left[G_{0}-N_{\mathrm{Fe}} \mu_{\mathrm{Fe}}^{0}-\frac{1}{2} N_{\mathrm{Ti}_{1}} \mu_{\mathrm{Y}_{2} \mathrm{TT}_{2} \mathrm{O}_{7}}^{0}+\frac{1}{2}\left(2 N_{\mathrm{Ti}}+3 N_{\mathrm{Y}_{2} \mathrm{O}_{3}}-N_{\mathrm{O}}\right)\left(\mu_{\mathrm{O}_{2}}^{0}+k T \ln p_{\mathrm{O}_{2}}\right)\right] .
\end{aligned}
$$

We further assume that temperature effects on the Gibbs free energy of the interface ensemble $\left(G_{0}\right)$ can be largely cancelled out with those of the two component bulks $\left(\mu_{\mathrm{Fe}}^{0}\right.$ and $\left.\mu_{\mathrm{Y}_{2} \mathrm{Ti}_{2} \mathrm{O}_{7}}^{0}\right)$ in Eq. 3. Thus we need only consider the temperature effect on the free energies of $\mathrm{O}_{2}\left(\mu_{\mathrm{O}_{2}}^{0}\right)$ using JANAF table values [60] for $\mathrm{O}_{2}$ molecules. An isothermal section of the interface phase diagram can be thus obtained, by plotting the calculated $\gamma_{\mathrm{I}}$ against $p_{\mathrm{O} 2}$ at any given temperature.

Fig. 2 shows the calculated isothermal section of the interface phase diagram at $T=1100 \mathrm{~K}$, with a direct comparison between with and without the temperature correction on $\mu_{\mathrm{O}_{2}}^{0}$. In either case, the GGA overbinding of $\mathrm{O}_{2}$ has been taken into account by following the instruction in Ref. [61]. Clearly, the non-stoichiometric interface energy is not a constant value, but varies with the ambient $T$ and $p_{\mathrm{O} 2}$, as suggested in Eq. (3). With the temperature correction on $\mu_{\mathrm{O}_{2}}^{0}$, the predicted interface energies shifted notably to higher $p_{\mathrm{O} 2}$ values. At this temperature, the Y/Ti-rich $(n s-2 Y 2 T i)$ interface dominates for $p_{\mathrm{O} 2}$ below $\sim e^{-28}$ while the O-rich $(n s-5 O)$ dominates for $p_{\mathrm{O} 2}$ above $\sim e^{-26}$. The critical $p_{\mathrm{O} 2}$ values for nonstoichiometric-to-stoichiometric transitions are marked as points $a$ and $b$. Apparently, with increasing $p_{\mathrm{O} 2}$, the most energetically favorable interface structure would change from the Y/Ti-rich to stoichiometric and then to the O-rich, following the same trend as seen for the $\mathrm{Y}_{2} \mathrm{Ti}_{2} \mathrm{O}_{7}(100)$ free surface [55]. But in contrast to the free surface results, the non-stoichiometric interfaces (both Y/Tiand O-rich) dominate here in a much wider range of $p_{\mathrm{O} 2}$, leaving an extremely narrow range of $p_{\mathrm{O} 2}$ $\left(-28<\ln p_{\mathrm{O} 2}<-26\right)$ for preferentially forming a stoichiometric interface.

Fig. 2 shows clearly how the interface structure evolves with temperature and the matrix $p_{\mathrm{O} 2}$. Thus one question immediately follows: which interface phase is expected in NFAs, at the given temperature, for example for $T=1100 \mathrm{~K}$. Experimentally determining the matrix $p_{\mathrm{O} 2}$ is very difficult. 
Fe itself does not internally oxidize in NFAs, but from a purely thermodynamic viewpoint, the upper limits of the matrix $p_{\mathrm{O} 2}$ are, in principle, controlled by equilibrium with an $\mathrm{Fe}$-oxide (i.e. $\mathrm{FeO}, \mathrm{Fe}_{2} \mathrm{O}_{3}$, or $\left.\mathrm{Fe}_{3} \mathrm{O}_{4}\right)$.

The critical oxygen partial pressure for $\mathrm{FeO}$ can be approximated as

$$
\ln p_{\mathrm{O}_{2}}=\frac{2 \Delta G_{\mathrm{FeO}}^{0}(T)}{R T}
$$

where $\Delta G^{0}(T)$ is the Gibbs standard formation energy of $\mathrm{FeO}$ at the temperature $T$, in accordance with the reaction $\mathrm{Fe}+\frac{1}{2} \mathrm{O}_{2} \rightarrow \mathrm{FeO}$. Here $p_{\mathrm{O} 2}$ is the matrix oxygen partial pressure reflecting the local oxygen activity at the interfaces. $R$ is the ideal gas constant, $8.314 \mathrm{~J} /(\mathrm{mol} \cdot \mathrm{K})$. Similarly,

$$
\begin{aligned}
& \ln p_{\mathrm{O}_{2}}=\frac{2}{3} \frac{\Delta G_{\mathrm{Fe}_{2} \mathrm{O}_{3}}^{0}(T)}{R T}, \\
& \ln p_{\mathrm{O}_{2}}=\frac{1}{2} \frac{\Delta G_{\mathrm{Fe}_{3} \mathrm{O}_{4}}^{0}(T)}{R T},
\end{aligned}
$$

for $\mathrm{Fe}_{2} \mathrm{O}_{3}$ and $\mathrm{Fe}_{3} \mathrm{O}_{4}$, respectively. Using $\Delta \mathrm{G}_{\mathrm{FeO}}^{0}=-200.67, \Delta \mathrm{G}_{\mathrm{Fe} 2 \mathrm{O} 3}^{0}=-537.171$, and $\Delta \mathrm{G}_{\mathrm{Fe} 304}^{0}=$ $-762.463 \mathrm{~kJ} / \mathrm{mol}$ for $T=1100 \mathrm{~K}$ as tabulated in the JANAF Tables [60], the oxidation of $\mathrm{FeO}, \mathrm{Fe}_{2} \mathrm{O}_{3}$, or $\mathrm{Fe}_{3} \mathrm{O}_{4}$ requires a threshold $p_{\mathrm{O} 2}$ of $\sim \mathrm{e}^{-44}, \mathrm{e}^{-42}$, or $\mathrm{e}^{-39}$, respectively. That is, the internal $p_{\mathrm{O} 2}$ must be below $\sim e^{-44}$ for $T=1100 \mathrm{~K}$ in order to form only the Y/Ti-oxides in NFAs. By mapping this upper limit of $p_{\mathrm{O} 2}$ onto the isothermal interface phase diagram (highlighted as the blue region in Fig. 2), we determine that the cube-on-cube ferrite $/ \mathrm{Y}_{2} \mathrm{Ti}_{2} \mathrm{O}_{7}$ interface at $T=1100 \mathrm{~K}$ is thermodynamically Y/Ti-rich, typically with a non-stoichiometric $2 \mathrm{Y} 2 \mathrm{Ti}(n s-2 Y 2 T i)$ termination. The corresponding interface energy is thus predicted to be no more than $0.8 \mathrm{~J} / \mathrm{m}^{2}$, falling into the reasonable value ranges of coherent $(0.005 \sim 0.2$ $\left.\mathrm{J} / \mathrm{m}^{2}\right)$ and semi-coherent $\left(0.2 \sim 0.8 \mathrm{~J} / \mathrm{m}^{2}\right)$ interfaces [62]. The $n s-2 Y 2 T i$-terminated $\mathrm{Y}_{2} \mathrm{Ti}_{2} \mathrm{O}_{7}$ interface corresponds to a chemical composition of $\mathrm{Y}_{2.5} \mathrm{Ti}_{2.5} \mathrm{O}_{7}$ that is favorably comparable to an EELS result of nano-oxide precipitates in NFAs as $\mathrm{Y}_{2.2} \mathrm{Ti}_{2.3} \mathrm{O}_{7}$ [22]. 
Fig. 2 The calculated isothermal section of the $\mathrm{Fe}(100) / \mathrm{Y}_{2} \mathrm{Ti}_{2} \mathrm{O}_{7}(100)$ interface phase diagram at $T=$ $1100 \mathrm{~K}$. Comparison is made between with and without the temperature correction on oxygen chemical potentials. In either case, the interface is predicted to be Y/Ti-rich in NFAs, typically with a non-stoichiometric 2Y2Ti (ns-2Y2Ti) termination.

However, for purposes of generality it is useful to treat the equilibrium thermodynamics baseline considering all possible solute oxidation reactions. Note, the transition pressure values (points $a$ and $b$ ) in Fig. 2 that determine the relative stabilities of the interface phases vary sensitively with temperature. Tracking these transitions at various temperatures enables the construction of the full equilibrium interface phase diagram in Fig. 3. The phase boundaries, which are constructed with these transition points, are labeled as solid curves $a$ and $b$ in Fig. 3. In addition, using the CALPHAD results [63, 64] and JANAF data [60], seven dotted and dot-dashed curves are calculated in accordance with various possible reaction thermodynamics, namely Curve (1): $\mathrm{Y}+\mathrm{O}_{2} \rightarrow \mathrm{Y}_{2} \mathrm{O}_{3}$, Curve (2): $\mathrm{Y}+\mathrm{Ti}+\mathrm{O}_{2} \rightarrow \mathrm{Y}_{2} \mathrm{Ti}_{2} \mathrm{O}_{7}$, Curve (3): $\mathrm{Ti}+\mathrm{O}_{2} \rightarrow \mathrm{TiO}$, Curve (4): $\mathrm{Y}_{2} \mathrm{O}_{3}+\mathrm{Ti}+\mathrm{O}_{2} \rightarrow \mathrm{Y}_{2} \mathrm{Ti}_{2} \mathrm{O}_{7}$ Curve (5): $\mathrm{Ti}+\mathrm{O}_{2} \rightarrow \mathrm{Ti}_{2} \mathrm{O}_{3}$, Curve (6): $\mathrm{Cr}+\mathrm{O}_{2} \rightarrow \mathrm{Cr}_{2} \mathrm{O}_{3}$, and Curve (7): $\mathrm{Fe}+\mathrm{O}_{2} \rightarrow \mathrm{Fe}_{\mathrm{x}} \mathrm{O}_{\mathrm{y}}$. Note that Curve (7) is plotted based on the formation of $\mathrm{FeO}$ only, which determines the lowest $p_{\mathrm{O} 2}$ limit for forming $\mathrm{Fe}_{\mathrm{x}} \mathrm{O}_{\mathrm{y}}$ (including $\mathrm{FeO}, \mathrm{Fe}_{2} \mathrm{O}_{3}$, and $\mathrm{Fe}_{3} \mathrm{O}_{4}$ ) in NFAs. The formation of $\mathrm{Fe}_{2} \mathrm{O}_{3}$ and $\mathrm{Fe}_{3} \mathrm{O}_{4}$ always requires a higher $p_{\mathrm{O} 2}$ than $\mathrm{FeO}$ (as seen in Fig. 2), and thus, for better clarity, is not explicitly shown in Fig. 3. For conditions above Curve (1), due to the extremely low values of $p_{\mathrm{O} 2}$, no solute oxidation can be expectable in NFAs, even at high temperatures; while for conditions below Curve (7), thermodynamically the iron matrix itself will be oxidized. The five dot-dashed curves (i.e. Curve (1), (3), (5), (6), and (7)), together with the two solid curves ( $a$ and $b$ ), divide the phase diagram into eight phase preference zones, namely (I) $\mathrm{Fe}\left(\mathrm{Cr} / \mathrm{Y} / \mathrm{Ti} / \mathrm{O}\right.$ ), (II) $\mathrm{Y}_{2} \mathrm{O}_{3}+\mathrm{Fe}\left(\mathrm{Cr} / \mathrm{Y} / \mathrm{Ti} / \mathrm{O}\right.$ ), (III) $\mathrm{Y}_{2} \mathrm{Ti}_{2} \mathrm{O}_{7}$ 
$(\mathrm{Y} / \mathrm{Ti}-\mathrm{rich})+\mathrm{Y}_{2} \mathrm{O}_{3}+\mathrm{TiO}+\mathrm{Fe}(\mathrm{Cr} / \mathrm{Ti} / \mathrm{O}),(\mathrm{IV}) \mathrm{Y}_{2} \mathrm{Ti}_{2} \mathrm{O}_{7}(\mathrm{Y} / \mathrm{Ti}$-rich $)+\mathrm{Y}_{2} \mathrm{O}_{3}+\mathrm{TiO} / \mathrm{TiO}_{2}+\mathrm{Fe}(\mathrm{Cr} / \mathrm{O}),(\mathrm{V}) \mathrm{Y}_{2} \mathrm{Ti}_{2} \mathrm{O}_{7}$ $(\mathrm{Y} / \mathrm{Ti}-\mathrm{rich})+\mathrm{Y}_{2} \mathrm{O}_{3}+\mathrm{TiO} / \mathrm{TiO}_{2}+\mathrm{Cr}_{2} \mathrm{O}_{3}+\mathrm{Fe}(\mathrm{O}), \quad(\mathrm{VI}) \mathrm{Y}_{2} \mathrm{Ti}_{2} \mathrm{O}_{7}(\mathrm{Y} / \mathrm{Ti}$-rich $)+\mathrm{Y}_{2} \mathrm{O}_{3}+\mathrm{TiO} / \mathrm{TiO}_{2}+\mathrm{Cr}_{2} \mathrm{O}_{3}+\mathrm{Fe}_{\mathrm{x}} \mathrm{O}_{\mathrm{y}}$, (VII) $\mathrm{Y}_{2} \mathrm{Ti}_{2} \mathrm{O}_{7}$ (stoi) $+\mathrm{Y}_{2} \mathrm{O}_{3}+\mathrm{TiO} / \mathrm{TiO}_{2}+\mathrm{Cr}_{2} \mathrm{O}_{3}+\mathrm{Fe}_{\mathrm{x}} \mathrm{O}_{\mathrm{y}}$, and (VIII) $\mathrm{Y}_{2} \mathrm{Ti}_{2} \mathrm{O}_{7}\left(\mathrm{O}\right.$-rich) $+\mathrm{Y}_{2} \mathrm{O}_{3}+\mathrm{TiO} / \mathrm{TiO}_{2}+$ $\mathrm{Cr}_{2} \mathrm{O}_{3}+\mathrm{Fe}_{\mathrm{x}} \mathrm{O}_{\mathrm{y}}$. The potential to form multiple oxide phases, associated with a wide range of possible $p_{\mathrm{O} 2}$ values, along with the extremely narrow Zone (VII), rationalizes the frequent failure to observe fully stoichiometric nano-oxide $\mathrm{Y}_{2} \mathrm{Ti}_{2} \mathrm{O}_{7}$ using various experimental techniques, as reviewed in Ref. [1].

Fig. 3 Calculated phase diagram for in-situ $\mathrm{Y}_{2} \mathrm{Ti}_{2} \mathrm{O}_{7}$ in NFAs. Zone I: single phase $\mathrm{Fe}(\mathrm{Cr} / \mathrm{Y} / \mathrm{Ti} / \mathrm{O})$ with dissolved $\mathrm{Y}, \mathrm{Ti}, \mathrm{Cr}$, and $\mathrm{O}$, Zone II: double phase region of $\mathrm{Y}_{2} \mathrm{O}_{3}+\mathrm{Fe}(\mathrm{Cr} / \mathrm{Y} / \mathrm{Ti} / \mathrm{O})$, Zone III: multi-phase region of $\mathrm{Y}_{2} \mathrm{Ti}_{2} \mathrm{O}_{7}(\mathrm{Y} / \mathrm{Ti}$-rich $)+\mathrm{Y}_{2} \mathrm{O}_{3}+\mathrm{TiO}+\mathrm{Fe}(\mathrm{Cr} / \mathrm{Ti} / \mathrm{O})$, Zone IV: multi-phase region of $\mathrm{Y}_{2} \mathrm{Ti}_{2} \mathrm{O}_{7}(\mathrm{Y} / \mathrm{Ti}$-rich $)+\mathrm{Y}_{2} \mathrm{O}_{3}+\mathrm{TiO} / \mathrm{TiO}_{2}+\mathrm{Fe}(\mathrm{Cr} / \mathrm{O})$, Zone $\mathrm{V}: \mathrm{Y}_{2} \mathrm{Ti}_{2} \mathrm{O}_{7}(\mathrm{Y} / \mathrm{Ti}$-rich $)+\mathrm{Y}_{2} \mathrm{O}_{3}+\mathrm{TiO} / \mathrm{TiO}_{2}+\mathrm{Cr}_{2} \mathrm{O}_{3}$ $+\mathrm{Fe}(\mathrm{O})$, Zone VI: $\mathrm{Y}_{2} \mathrm{Ti}_{2} \mathrm{O}_{7}(\mathrm{Y} / \mathrm{Ti}$-rich $)+\mathrm{Y}_{2} \mathrm{O}_{3}+\mathrm{TiO} / \mathrm{TiO}_{2}+\mathrm{Cr}_{2} \mathrm{O}_{3}+\mathrm{Fe}_{\mathrm{x}} \mathrm{O}_{\mathrm{y}}$, Zone VII: $\mathrm{Y}_{2} \mathrm{Ti}_{2} \mathrm{O}_{7}(\mathrm{stoi})+\mathrm{Y}_{2} \mathrm{O}_{3}$ $+\mathrm{TiO} / \mathrm{TiO}_{2}+\mathrm{Cr}_{2} \mathrm{O}_{3}+\mathrm{Fe}_{\mathrm{x}} \mathrm{O}_{\mathrm{y}}$, Zone VIII: $\mathrm{Y}_{2} \mathrm{Ti}_{2} \mathrm{O}_{7}(\mathrm{O}-$ rich $)+\mathrm{Y}_{2} \mathrm{O}_{3}+\mathrm{TiO} / \mathrm{TiO}_{2}+\mathrm{Cr}_{2} \mathrm{O}_{3}+\mathrm{Fe}_{\mathrm{x}} \mathrm{O}_{\mathrm{y}}$.

Further, it should be noted that the actual matrix $p_{\mathrm{O} 2}$ may be far in excess of thermodynamic equilibrium values for $\mathrm{Y}_{2} \mathrm{Ti}_{2} \mathrm{O}_{7}$ precipitation. Significant internal oxidation of $\mathrm{Fe}$, or even $\mathrm{Cr}$, has not been observed in the actual NFAs, and appears to be kinetically prohibited. Here we consider neither non-equilibrium $p_{\mathrm{O} 2}$, nor kinetics, but rather adopt a limiting and fixed thermodynamic viewpoint as the foundation for assessing the Y/Ti-rich $(n s-2 Y 2 T i)$ interface structure and the interface interactions with helium and point defects.

\subsection{Helium trapping at nano-oxide interfaces}


The major significance of bulk-phase oxides to helium trapping and tolerance in NFAs has been shown in our previous studies $\left(\mathrm{Y}_{2} \mathrm{Ti}_{2} \mathrm{O}_{7}[32]\right.$ and $\mathrm{Y}_{2} \mathrm{TiO}_{5}$ [33]). However, for a full understanding of helium ultimate fates in NFAs, the possible roles of nano-oxide interfaces must be also examined. We have suggested that, from the first-principles calculations, the $\mathrm{Y}_{2} \mathrm{Ti}_{2} \mathrm{O}_{7}$ interfaces with the cube-on-cube OR are thermodynamically Y/Ti-rich (see Fig. 2 and 3). In this section, we assess the capability of such oxide interfaces to trap helium. Both perfect and the defective (vacancy and helium-containing) ferrite $/ \mathrm{Y}_{2} \mathrm{Ti}_{2} \mathrm{O}_{7}$ interfaces are carefully examined.

In the case of a clean, defect-free Y/Ti-rich termination, various interfacial interstitial sites for helium were considered. Full structural relaxation calculations showed that five configurations are potentially stable for helium trapping, including two open interstitial sites $\left(\mathrm{He}_{\mathrm{A}}^{\mathrm{i}}\right.$ and $\left.\mathrm{He}_{\mathrm{B}}^{\mathrm{i}}\right)$, one Ti-tetrahedron site on the interface $\left(\mathrm{He}_{\mathrm{T}}^{\mathrm{i}}\right)$, and two octahedral interstitial sites in sub-layers $\left(\mathrm{He}^{\mathrm{s}}{ }_{\mathrm{A}}\right.$ and $\left.\mathrm{He}^{\mathrm{s}}{ }_{\mathrm{B}}\right)$. Fig. 4 plots the five feasible interfacial helium structures after full relaxation. For the vacancycontaining Y/Ti-rich interface, energetic calculations were performed for various possible vacancy sites, created by removing one $\mathrm{Fe}, \mathrm{Y}, \mathrm{Ti}$, or $\mathrm{O}$ atom from the interface. The results suggested that the iron vacancy requires the least energy expense, and is much lower than any other types of vacancy at the interface. Thus we need only consider the iron vacancy and label it as $\mathrm{V}^{\mathrm{i}}$ in Fig. 5(a). Up to three helium atoms were then introduced to the interstitial and vacancy sites. Fig. 5 plots the total of seven interfacial helium-vacancy clusters that result, including zero to three helium atoms sharing one interfacial vacancy [labeled as $\mathrm{V}^{\mathrm{i}}, \mathrm{He}^{\mathrm{i}} \mathrm{v},(2 \mathrm{He})^{\mathrm{i}} \mathrm{v}$, and $(3 \mathrm{He})^{\mathrm{i}} \mathrm{v}$, respectively] and zero to two helium atoms occupying the interfacial vacancy accompanied by an interfacial helium $\left(\mathrm{He}^{\mathrm{i}} \mathrm{T}\right)$ [labeled as $\mathrm{He}^{\mathrm{i}}{ }_{\mathrm{T}}+\mathrm{V}^{\mathrm{i}}, \mathrm{He}^{\mathrm{i}}{ }_{\mathrm{v}}+\mathrm{He}^{\mathrm{i}} \mathrm{T}$, and $(2 \mathrm{He})^{\mathrm{i}}{ }_{\mathrm{v}}+\mathrm{He}^{\mathrm{i}}{ }_{\mathrm{T}}$, respectively] .

The relative stabilities of these helium-trapped interface structures can be evaluated using the corresponding formation energy, $E_{f}$, defined as 


$$
E_{f}=E_{\mathrm{d}}-E_{0}-m \cdot \mu_{\mathrm{He}}+n \cdot \mu_{\mathrm{Fe}}
$$

where $E_{\mathrm{d}}$ is the total energy of a defective interface, $E_{0}$ is the total energy of the clean, defect-free interface, $\mu_{\mathrm{He}}$ is the chemical potential of helium as an isolated atom, and $\mu_{\mathrm{Fe}}$ is the chemical potential of iron in its pure state. $m$ is the number of helium atoms in the defective interface, and $n$ is the number of iron vacancies if applicable.

Fig. 4 Possible interstitial sites for helium on the Y/Ti-rich interface: (a) $\mathrm{He}^{\mathrm{i}}{ }_{\mathrm{A}}$, (b) $\mathrm{He}_{\mathrm{B}}{ }^{\mathrm{i}}$, (c) $\mathrm{He}^{\mathrm{i}} \mathrm{T}$, (d) $\mathrm{He}^{\mathrm{s}} \mathrm{A}$, and (e) $\mathrm{He}_{\mathrm{B}}^{\mathrm{s}}$. Corresponding top views of interfacial layers are shown at the bottom.

Fig. 5 Possible configurations of helium-vacancy clusters on the Y/Ti-rich interface: (a) $\mathrm{V}^{\mathrm{i}}$, (b) $\mathrm{He}^{\mathrm{i}}{ }_{\mathrm{T}}+\mathrm{V}^{\mathrm{i}}$, (c) $\mathrm{He}^{\mathrm{i}} \mathrm{v}$, (d) $\mathrm{He}^{\mathrm{i}}{ }_{\mathrm{v}}+\mathrm{He}^{\mathrm{i}} \mathrm{T}$, (e) $(2 \mathrm{He})^{\mathrm{i}} \mathrm{v}$, (f) $(2 \mathrm{He})^{\mathrm{i}} \mathrm{v}+\mathrm{He}^{\mathrm{i}} \mathrm{T}$, and (g) (3He) ${ }^{\mathrm{i}} \mathrm{v}$. Corresponding top views of interfacial layers are shown at the bottom.

Table 1 summarizes the calculated formation energies of these interface structures based on Eq. 7 . By referring to our previous study on helium trapping in bulk $\mathrm{Y}_{2} \mathrm{Ti}_{2} \mathrm{O}_{7}$ versus in iron [32], it is clear that the helium energy is effectively the same at interstitial sites both on the interface and inside the oxide interior. That is, the lowest formation energy of interstitial helium on the interface $\left(\mathrm{He}_{\mathrm{T}}^{\mathrm{i}}=0.95\right.$ $\mathrm{eV})$ is nearly identical to that in bulk $\mathrm{Y}_{2} \mathrm{Ti}_{2} \mathrm{O}_{7}\left(\mathrm{He}_{\text {octa }}^{\mathrm{I}}=0.94 \mathrm{eV}\right)$, and well within the calculational uncertainties. Both are significantly lower than that of substitutional helium occupying a vacancy in the iron matrix $\left(\mathrm{He}_{\mathrm{v}}=2.28 \mathrm{eV}\right)$. The formation energy of an interface vacancy $\left(\mathrm{V}^{\mathrm{i}}=0.62 \mathrm{eV}\right)$ is also much lower than that in matrix iron $\left(\mathrm{V}_{\mathrm{Fe}}=2.14 \mathrm{eV}\right)$. We also note that the formation energies of interstitial $\mathrm{He}_{\mathrm{A}}^{\mathrm{S}}$ and $\mathrm{He}_{\mathrm{B}}^{\mathrm{S}}(1.43$ and $1.29 \mathrm{eV})$ at sub-interface layers are higher than that in bulk $\mathrm{Y}_{2} \mathrm{Ti}_{2} \mathrm{O}_{7}\left(\mathrm{He}^{\mathrm{I}}\right.$ octa $\left.=0.94 \mathrm{eV}\right)$. This difference, to some extent, is related to interfacial coherent strains. 
Table 1 Calculated formation energies of various helium-trapped interface structures

Note that the formation energies for interfacial helium-vacancy clusters, i.e. $\mathrm{He}^{\mathrm{i}} \mathrm{T}^{\mathrm{i}} \mathrm{V}^{\mathrm{i}}, \mathrm{He}^{\mathrm{i}}{ }_{\mathrm{v}}$, $\mathrm{He}^{\mathrm{i}}{ }_{\mathrm{v}}+\mathrm{He}^{\mathrm{i}} \mathrm{T},(2 \mathrm{He})_{\mathrm{v}}^{\mathrm{i}},(2 \mathrm{He})^{\mathrm{i}}{ }_{\mathrm{v}}+\mathrm{He}^{\mathrm{i}}{ }_{\mathrm{T}}$ and $(3 \mathrm{He})^{\mathrm{i}} \mathrm{v}$ in Table 1, include the vacancy formation energy (according to Eq. 7). The total number of thermal vacancies is constant, as they are replenished by generation at sites like dislocation jogs. In this framework, substitutional helium can be simply seen as an alloy constituent element. In other words, the vacancy loses its identity and energy upon conversion to a lattice site occupied by helium. Thus we are able to compare all of the above formation energies with reference to the interface vacancy energy $\left(\mathrm{V}^{\mathrm{i}}\right)$ in Fig. 6. It is shown in Fig. 6 that the proper thermodynamic $\mathrm{He}^{\mathrm{i}}{ }_{\mathrm{v}}$ is now $0.74 \mathrm{eV}$, only slightly lower than those of $\mathrm{He}^{\mathrm{i}}+\mathrm{V}^{\mathrm{i}}(0.80 \mathrm{eV})$ on the interface and $\mathrm{He}^{\mathrm{I}}{ }_{\text {octa }}(0.94 \mathrm{eV}$ [32]) in the oxide interior. All these values are significantly lower than that of helium at matrix iron vacancies $\left(\mathrm{He}_{\mathrm{v}}=2.28 \mathrm{eV}\right.$ [32]). Thus helium will partition from the ferrite matrix not only to the bulk oxides but also (possibly preferentially) to their interfaces. Concentrations of interface and bulk vacancies in excess of their equilibrium values are generated by severe deformation during ball milling, as well as under irradiation. We will not consider this further in the thermodynamic framework that we adopt here, but simply regard the vacancies as fully available. It is suggested in Fig. 6 that as the helium concentration increases, it tends to consume single individual interface vacancies and interstitials to the extent possible before forming multiple helium-vacancy clusters on the interface [such as $(2 \mathrm{He})^{\mathrm{i}} \mathrm{v},(2 \mathrm{He})^{\mathrm{i}} \mathrm{v}+\mathrm{He}^{\mathrm{i}} \mathrm{T}$, and $(3 \mathrm{He})^{\mathrm{i}} \mathrm{v}$ ], and/or in the oxide interior [such as $2\left(\mathrm{He}_{\text {octa }}^{\mathrm{I}}\right), 2-\mathrm{He}^{\mathrm{I}}{ }_{\text {octa }},(2 \mathrm{He})^{\mathrm{I}}{ }_{\text {octa, }} 3\left(\mathrm{He}^{\mathrm{I}}{ }_{\text {octa }}\right), 3-\mathrm{He}^{\mathrm{I}}$ octa , and $(3 \mathrm{He})^{\mathrm{I}}$ octa]

Fig. 6 Formation energies of helium-vacancy clusters on the interface compared to those in iron and in 
the oxide bulk as reported in Ref. [32].

The detailed balance between the various locations governs the site-dependent helium concentrations. This in turn depends on the size of the nano-oxide. As seen in Table 1, the energy per average helium atom is $\sim 1.4 \mathrm{eV} / \mathrm{He}$-atom for small helium clusters [e.g., $(2 \mathrm{He})^{\mathrm{i}} \mathrm{v}$ or $(3 \mathrm{He})^{\mathrm{i}} \mathrm{v}$ ] sharing an interface vacancy, and is comparable to the value of $\sim 1.5 \mathrm{eV} / \mathrm{He}$-atom for $(2 \mathrm{He})^{\mathrm{I}}$ octa or $(3 \mathrm{He})^{\mathrm{I}}$ octa sharing an interstitial site in the oxide interior [32]. The corresponding Boltzmann factors between bulk and interface sites are small, i.e. the fractional concentrations would all be roughly similar. These small helium clusters may act as nucleation sites for larger equilibrium helium fluid-gas bubbles with even lower energies per atom beyond a minimum size [32]. Bubbles that are initially over-pressurized quickly equilibrate by absorbing a sufficient number of vacancies. The broader implication of the helium management in NFAs will be discussed further in Sec.3.4.

\subsection{Implications of the helium management and fate in NFAs}

Fig. 6 and detailed balance considerations suggest that helium is preferentially associated with the nano-oxide $\mathrm{Y}_{2} \mathrm{Ti}_{2} \mathrm{O}_{7}$, both at its interface and in the interior. This is qualitatively consistent with the experimentally observed distribution of helium bubbles in NFAs. Fig. 7 shows an overlapped bright-field transmission electron microscopy (TEM) micrograph of a dual helium-Fe ion irradiated 14YWT NFA (MA957) at $650^{\circ} \mathrm{C}$ at a radiation damage level of 48 displacements per atom (dpa) and 2200 appm helium. Here, the images of helium bubbles were taken in under-focus (white features indicated by blue arrows) and the nano-oxides in focus (light gray features indicated by red arrows) conditions. The overlapping of helium bubbles and nano-oxides indicates their high degree of mutual association. A likely scenario is that helium is initially deeply trapped in the oxide, but forms interface 
bubbles that are sufficiently large (> 0.5-0.6 nm) such that the corresponding chemical potential in the fluid-gas phase is lower than in the oxide [32].

Fig. 7 The high degree of helium bubble and nano-oxide association in a 14YWT NFA dual ion irradiated at $650^{\circ} \mathrm{C}$ to 48 displacements per atom and 2200 appm helium, with some examples highlighted by the blue and red arrows, indicating the bubbles and nano-oxides respectively.

To further clarify the helium management and fate in NFAs, we illustrate the energetics of helium partitioning and the sequence of events leading to interface bubble nucleation in Fig. 8(a) and (b), respectively. The bars for the grain boundary (GB) energies represent the range of $\mathrm{V}^{\mathrm{GB}}$ and $\mathrm{He}_{\mathrm{V}}{ }^{\mathrm{GB}}$ values by DFT in the literature [65-68]. These results strongly suggest that nano-oxides prevent large quantities of vacancies (process b1) and helium (process b2) from reaching GBs. Thus the bubble sizes both in the matrix and on GBs remain far smaller than the critical radius for conversion to growing voids (under irradiation) or creep cavities (under stress).

Interface bubble formation involves two sources of excess energy: the free surfaces created by the bubble, and the work of pressurizing helium from its reference state to the condition in the bubbles, as discussed in previous studies $[1,32,69,70]$. In the simple capillary approximation framework, both terms are estimated as $\sim 2 \gamma_{\mathrm{e}} / \mathrm{r}_{\mathrm{b}}$, where $\gamma_{\mathrm{e}}$ is an effective surface energy and $\mathrm{r}_{\mathrm{b}}$ is the radius of the bubble. The bubbles equilibrate to accommodate the trapped helium by absorbing vacancies (process b3). That is, the oxide interfaces actually act as heterogeneous sites for helium bubble nucleation. Obviously, ultrahigh densities of nano-oxides disperse helium into even smaller sizes up to very high temperatures, whereas fewer numbers of larger oxides could actually promote swelling by quickly forming interface bubbles that are large enough to convert to growing voids [1, 71]. 
Fig. 8 (a) Energies of forming vacancies and trapping helium at different locations in NFAs. Locations include the ferrite matrix, the bulk oxides, the oxide interfaces, and the iron grain boundaries. (b) The schematic formation of interfacial helium bubbles in NFAs. The superscript '*' refers to the DFT results available in the literature.

\section{Conclusions}

We have performed a density functional theory based study to assess the important roles of $\mathrm{Y}_{2} \mathrm{Ti}_{2} \mathrm{O}_{7}$ interfaces in helium management in NFAs. The full interface phase diagram was obtained to predict the lowest energy ferrite $/ \mathrm{Y}_{2} \mathrm{Ti}_{2} \mathrm{O}_{7}$ interface structures. Vacancy and helium interactions with the cube-on-cube oxide interfaces were examined in a framework of the equilibrium thermodynamics of NFAs. The current results were compared to our previous calculations for bulk $\mathrm{Y}_{2} \mathrm{Ti}_{2} \mathrm{O}_{7}$ as well as to published descriptions of helium interactions with GB. This leads to the following conclusions.

(i) The ferrite $/ \mathrm{Y}_{2} \mathrm{Ti}_{2} \mathrm{O}_{7}$ interface with the cube-on-cube orientation relationship of $\{100\}\langle 100\rangle_{\mathrm{Fe}} / /$ $\{100\}<100>_{\text {Y } 2 \text { Ti2O7 }}$ can be Y/Ti-rich, stoichiometric, or O-rich, depending on the internal oxygen partial pressure and temperature.

(ii) In the thermodynamic equilibrium framework, the calculated interface phase diagram predicts that the ferrite $/ \mathrm{Y}_{2} \mathrm{Ti}_{2} \mathrm{O}_{7}$ interfaces are $\mathrm{Y} / \mathrm{Ti}$-rich, over a wide temperature range of interest. This partially rationalizes the possible non-stoichiometric nature of $\mathrm{Y}_{2} \mathrm{Ti}_{2} \mathrm{O}_{7}$ precipitates often observed in some cases. Note, there is a wider range of possibilities for non-equilibrium results.

(iii) Vacancy formation energies are lower at the ferrite $/ \mathrm{Y}_{2} \mathrm{Ti}_{2} \mathrm{O}_{7}$ interface than at ferrite GBs, and the interfacial helium formation energies are close to that for helium trapping inside the bulk oxides. Thus helium can be first sequestered by the nano-oxides before it enters an even lower fluid-gas 
energy state in sufficiently large interface bubbles.

(iv) The large number of nm-sized bubbles trap most of the helium and act as sinks, or recombination (self-healing) sites, for displacement damage defects. This imbues NFAs with a remarkable degree of irradiation tolerance. 


\section{Acknowledgements}

The authors are grateful for the support from the DOE Office of Fusion Energy Sciences (grant No. DE-FG03-94ER54275) and the National Science Foundation of China (No. 51471189, 51171211, and 51471049). One of the authors (Y. Jiang) also gratefully acknowledges the partial support from the National Basic Research Program of China (sub-contract No. 2014CB644001-2), and the National Key Laboratory of Powder Metallurgy at Central South University. The computational resource at the High Performance Computing Center of Central South University is also gratefully acknowledged. 


\section{References}

[1] G. R. Odette, M. J. Alinger, B.D. Wirth, Recent developments in irradiation-resistant steels, Annu. Rev. Mater. Res. 38 (2008) 471-503.

[2] S. Ukai, S. Mizuta, T. Yoshitake, T. Okuda, M. Fujiwara, S. Hagi, T. Kobayashi, Tube manufacturing and characterization of oxide dispersion strengthened ferrite steels, J. Nucl. Mater. 283 (2000) 702-706.

[3] S. Ukai, T. Kaito, S. Ohtsuka, T. Narita, T. Fujiwara, T. Kobayashi, Production and properties of nano-scale oxide dispersion strengthened (ODS) 9Cr martensitic steel claddings, ISIJ Int. 43 (2003) 2038-2045.

[4] R. L. Klueh, P. J. Maziasz, I. S. Kim, L. Heatherly, D. T. Hoelzer, N. Hashimoto, E. A. Kenik, K. Miyahara, Tensile and creep properties of an oxide dispersion-strengthened ferrite steel, J. Nucl. Mater. 307 (2002) 773-777.

[5] R. L. Klueh, N. Hashimoto, P. J. Maziasz, Development of new nano-particle-strengthened martensitic steels, Scripta Mater. 53 (2005) 275-280.

[6] D. J. Larson, P. J. Maziasz, I. S. Kim, K. Miyahara, Three-dimensional atom probe observation of nanoscale titanium-oxygen clustering in an oxide-dispersion-strengthened Fe-12Cr-3W-0.4Ti+ $\mathrm{Y}_{2} \mathrm{O}_{3}$ ferrite alloy, Scripta. Mater. 44 (2001) 359-364.

[7] M. K. Miller, D. T. Hoelzer, E. A. Kenik, K. F. Russell, Nanometer scale precipitation in ferrite MA/ODS alloy MA957, J. Nucl. Mater. 329 (2004) 338-341.

[8] M. K. Miller, D. T. Hoelzer, E. A. Kenik, K. F. Russell, Stability of ferrite MA/ODS alloys at high temperatures, Intermetallics, 13 (2005) 387-392.

[9] M. K. Miller, E. A. Kenik, K. F. Russell, L. Heatherly, D. T. Hoelzer, P. J. Maziasz, Atom probe tomography of nanoscale particles in ODS ferrite alloys, Mater. Sci. Eng. A - Struct. Mater. Prop. 
Microstruct. Process, 353 (2003) 140-145.

[10] M. K. Miller, K. F. Russell, D. T. Hoelzer, Characterization of precipitates in MA/ODS ferrite alloys, J.Nucl. Mater. 351 (2006) 261-268.

[11] G. R. Odette, D. T. Hoelzer, Irradiation-tolerant nanostructured ferrite alloys: Transforming helium from a liability to an asset, JOM, 62 (2010) 84-92.

[12] G. R. Odette, P. Miao, D. J. Edwards, T. Yamamoto, R.J. Kurtz, H. Tanigawa, Helium transport, fate and management in nanostructured ferrite alloys: In situ helium implanter studies, J. Nucl. Mater. 417 (2011) 1001-1004.

[13] G. R. Odette, Recent Progress in Developing and Qualifying Nanostructured Ferrite Alloys for Advanced Fission and Fusion Applications, JOM, 66 (2014) 2427-2441.

[14] Y. Wu, E. Haney, N. Cunningham, G. R. Odette, Transmission electron microscopy characterization of the nanofeatures in nanostructured ferrite alloy MA957, Acta. Mater. 60 (2012) $3456-3468$.

[15] L. Barnard, G. R. Odette, I. Szlufarska, D. Morgan, An ab initio study of Ti-Y-O nanocluster energetics in nanostructured ferrite alloys, Acta. Mater. 60 (2012) 935-947.

[16] M. J. Alinger, G. R. Odette, D. T. Hoelzer, On the role of alloy composition and processing parameters in nano-cluster formation and dispersion strengthening in nano-structured ferrite alloys, Acta. Mater. 57 (2009) 392-406.

[17] M. Ohnuma, J. Suzuki, S. Ohtsuka, S. W. Kim, T. Kaito, M. Inoue, H. Kitazawa, A new method for the quantitative analysis of the scale and composition of nano-sized oxide in 9Cr-ODS steel, Acta. Mater. 57 (2009) 5571-5581.

[18] Z. Oksiuta, P. Olier, Y. de Carlan, N. Baluc, Development and characterization of a new ODS ferrite steel for fusion reactor application, J. Nucl. Mater. 393 (2009) 114-119. 
[19] A. Etienne, N. Cunningham, Y. Wu, G. R. Odette, Effects of friction stir welding and post-weld annealing on nanostructured ferrite alloy, Mater. Sci. Technol. 27 (2011) 724-728.

[20] N. Cunningham, E. Stergar, E. Marquis, A. Etaine, G. R. Odette, Inter laboratory atom probe tomography characterization study of the nanofeatures and bulk-matrix composition of US MA957, Fusion Reactor Materials Program Semi Annual Progress Report, DOE/ER-0313/50 (2011).

[21] Y. Wu, E. Haney, N. Cunningham, G. R. Odette, TEM characterization of the structure and composition of the nanofeatures in nanostructured ferrite alloy MA957, Fusion Reactor Materials Program Semi Annual Progress Report, DOE/ER-0313/50 (2011).

[22] M. Klimiankou, R. Lindau, A. Möslang, Energy-filtered TEM imaging and EELS study of ODS particles and Argon-filled cavities in ferrite-martensitic steels, Micron, 36 (2005) 1-8.

[23] S. Yamashita, S. Ohtsuka, N. Akasaka, S. Ukai, S. Ohnuki, Formation of nanoscale complex oxide particles in mechanically alloyed ferrite steel, Philos. Mag. Lett. 84 (2004) 525-529.

[24] S. Yamashita, N. Akasaka, S. Ohnuki, Nano-oxide particle stability of 9-12Cr grain morphology modified ODS steels under neutron irradiation, J. Nucl. Mater. 329 (2004) 377-381.

[25] H. Kishimoto, R. Kasad, O. Hashitomi, A. Kimura, Stability of Y-Ti complex oxides in Fe-16Cr-0.1Ti ODS ferrite steel before and after heavy-ion irradiation, J. Nucl. Mater. 386 (2009) 533-536.

[26] H. Sakasegawa, M. Tamura, S. Ohtsuka, S. Ukai, H. Tanigawa, A. Kohyama, M. Fujiwara, Precipitation behavior of oxide particles in mechanically alloyed powder of oxide-dispersion-strengthened steel, J. Alloys Compd. 452 (2008) 2-6.

[27] H. Sakasegawa, L. Chaffron, F. Legendre, L. Boulanger, T. Cozzika, M. Brocq, Y. de Carlan, Correlation between chemical composition and size of very small oxide particles in the MA957 
ODS ferrite alloy, J. Nucl. Mater. 384 (2009) 115-118.

[28] M. Klimiankou, R. Lindau, A. Möslang, TEM characterization of structure and composition of nanosized ODS particles in reduced activation ferrite-martensitic steels, J. Nucl. Mater. 329 (2004) $347-352$.

[29] T. Okuda, M. Fujiwara, Dispersion behavior of oxide particles in mechanically alloyed ODS steel, J. Mater. Sci. Lett. 14 (1995) 1600-1603.

[30] D. Bhattacharyya, P. Dickerson, G. R. Odette, S. A. Maloy, A. Misra, M. A. Nastasi, On the structure and chemistry of complex oxide nanofeatures in nanostructured ferrite alloy U14YWT, Philos. Mag., 92 (2012) 2089-2107.

[31] C. Lu, Z. Lu, R. Xie, C. Liu, L. Wang, Microstructure of a 14Cr-ODS ferritic steel before and after helium ion implantation, J. Nucl. Mater. 455 (2014) 366-370.

[32] L. Yang, Y. Jiang, G. R. Odette, T. Yamamoto, Z. Liu, Y. Liu, Trapping helium in $\mathrm{Y}_{2} \mathrm{Ti}_{2} \mathrm{O}_{7}$ compared to in matrix iron: A first principles study, J. Appl. Phys. 115 (2014) 143508.

[33] Y. Jin, Y. Jiang, L. Yang, G. Lan, G. R. Odette, T. Yamamoto, J. Shang, Y. Dang, First principles assessment of helium trapping in $\mathrm{Y}_{2} \mathrm{TiO}_{5}$ in nano-featured ferrite alloys, J. Appl. Phys., 116: 1435011 (2014).

[34] J. Ribis, Y. de Carlan, Interfacial strained structure and orientation relationships of the nanosized oxide particles deduced from elasticity-driven morphology in oxide dispersion strengthened materials, Acta Mater. 60 (2012) 238-252.

[35] J. Ciston, Y. Wu, G.R. Odette, P. Hosemann, The structure of nanoscale precipitates and precipitate interfaces in an oxide dispersion strengthened steel, Microsc. Microanal. 18 (Suppl 2) (2012) 760-761.

[36] K. Dawson, G. J. Tatlock, Characterization of nanosized oxides in ODM401 oxide dispersion 
strengthened steel, J. Nucl. Mater. 444 (2014) 252-260.

[37] T. Stan, Y. Wu, G. R. Odette, K. E. Sickafus, H. A. Dabkowska, B. D. Gaulin, Fabrication and characterization of naturally selected epitaxial $\mathrm{Fe}-\{111\} \mathrm{Y}_{2} \mathrm{Ti}_{2} \mathrm{O}_{7}$ mesoscopic interfaces: some potential implications to nano-oxide dispersion-strengthened steels, Metall. Mater. Trans. A, 10 (2013) 4505-4512.

[38] G. Kresse, J. Furthmüller, http://cms.mpi.univie.ac.at/vasp/vasp/vasp.html. For more information, see G. Kresse andJ. Hafner, Phys. Rev. B: Condens. Matter, 47 (1993) 558; and also G. Kresse, J. Furthmüller, Phys. Rev. B: Condens. Matter, 54 (1996) 11169.

[39] G. Kresse, J. Joubert, From ultrasoft pseudopotentials to the projector augmented-wave method, Phys. Rev. B. 59 (1999) 1758-1775.

[40] P. Vinett, J. H. Rose, J. Ferrante, J. R. Smith, Universal features of the equation of state of solids, J. Phys.Condens. Matter 1 (1989) 1941-1963.

[41] K. J. Caspersen, A. Lew, M. Ortiz, E. A. Carter, Importance of shear in the bcc-to-hcp transformation in iron, Phys. Rev. Lett. 93 (2004) 115501.

[42] G. Simmons, H. Wang, Single Crystal Elastic Constants and Calculated Aggregate Properties: A Handbook (M.I.T. Press, Cambridge, MA, 1971).

[43] J. Leese, A. E. Lord, Jr., Elastic stiffness coefficients of single-crystal iron from room temperature to $500^{\circ} \mathrm{C}$, J. Appl. Phys. 39 (1968) 3986-3988.

[44] D. J. Dever, Temperature dependence of the elastic constants in $\alpha$-iron single crystals: relationship to spin order and diffusion anomalies, J. Appl. Phys. 43 (1972) 3293-3301.

[45] Y. Jiang, J. R. Smith, and G. R. Odette, Prediction of structural, electronic and elastic properties of $\mathrm{Y}_{2} \mathrm{Ti}_{2} \mathrm{O}_{7}$ and $\mathrm{Y}_{2} \mathrm{TiO}_{5}$, Acta. Mater. 58 (2010) 1536-1543.

[46] M. A. Subramanian, G. Aramudan, G. V. Subba Rao, Oxide pyrochlores - A review, Prog. Solid 
State Chem. 15 (1983) 55-143.

[47] M. Glerup, O. F. Nielsen, F. W. Poulsen, The structural transformation from the pyrochlore structure, $\mathrm{A}_{2} \mathrm{~B}_{2} \mathrm{O}_{7}$, to the fluorite structure, $\mathrm{AO}_{2}$, studied by Raman spectroscopy and defect chemistry modeling, J. Solid State Chem. 160 (2001) 25-32.

[48] S. M. Haile, B. J. Wuensch, E. Prince, Neutron rietveld analysis of anion and cation disorder in the fast-ion conducting pyrochlore system $\mathrm{Y}_{2}\left(\mathrm{Zr}_{\mathrm{x}} \mathrm{Ti}_{1-\mathrm{x}}\right)_{2} \mathrm{O}_{7}$, Mater. Res. Soc. Symp. Proc. 166 (1990)81-86.

[49] L. F. He, J. Shirahata, T. Nakayama, T. Suzuki, H. Suematsu, I. Ihara, Y.W. Bao, T. Komatsu, K. Niihara, Mechanical properties of $\mathrm{Y}_{2} \mathrm{Ti}_{2} \mathrm{O}_{7}$, Scripta Mater. 64 (2011) 548-551.

[50] W. Kohn, L. J. Sham, Self-Consistent Equations Including Exchange and Correlation Effects, Phys. Rev. 140 (1965) A1133.

[51] J. P. Perdew, J. A. Chevary, S. H. Vosko, K. A. Jackson, M. R. Pederson, D. J. Singh, C. Fiolhais, Atoms, molecules, solids, and surfaces: applications of the generalized gradient approximation for exchange and correlation, Phys. Rev. B. 46 (1992) 6671-6687.

[52] J. P. Perdew, K. Burke, M. Ernzerhof, Generalized gradient approximation made simple, Phys. Rev. Lett. 77 (1996) 3865-3868.

[53] J. R. Smith, Y. Jiang, A. G. Evans, Adhesion of the $\gamma-\mathrm{Ni}(\mathrm{Al}) / \alpha-\mathrm{Al}_{2} \mathrm{O}_{3}$ interface: a first-principles assessment, Int. J. Mater. Res. 98 (2007) 1214-1221.

[54] Y. Jiang, J. R. Smith, A. G. Evans, First principles assessment of metal/oxide interface adhesion", Appl. Phys. Letts. 92 (2008) 141918.

[55] L. Yang, Y. Jiang, G. R. Odette, W. C. Zhou, Z. Liu, Y. Liu, Nonstoichiometry and relative stabilities of $\mathrm{Y}_{2} \mathrm{Ti}_{2} \mathrm{O}_{7}$ polar surfaces, Acta Mater. 61 (2013) 7260-7270.

[56] W. Zhang, J. R. Smith, X. G. Wang, A. G. Evans, Influence of sulfur on the adhesion of the 
Nickle/Alumina interface, Phys. Rev. B 67 (2003) 245414.

[57] G. Lan, Y. Jiang, D. Yi, S. Liu, Theoretical prediction of impurity effects on the internally oxidized metal/oxide interface: the case study of $\mathrm{S}$ on $\mathrm{Cu} / \mathrm{Al}_{2} \mathrm{O}_{3}$, Phys. Chem. Chem. Phys. 14 (2012) 11178-11184.

[58] G. Lan, Y. Wang, Y. Jiang, H. Zhou, D. Yi, Effects of rare-earth dopants on the thermally grown $\mathrm{Al}_{2} \mathrm{O}_{3} / \mathrm{Ni}(\mathrm{Al})$ interface: the first-principles prediction, J. Mater. Sci. 49 (2014) 2640-2646.

[59] D. T. Hoelzer, J. Bentley, M. A. Sokolov, M. K. Miller, G. R. Odette, M. J. Alinger, Influence of particle dispersions on the high-temperature strength of ferrite alloys, J. Nucl. Mater., 367-360 (2007)166-172.

[60] M. W. Chase, Jr, NIST-JANAF Thermochemical Tables, Fourth Edition, J. Phys. Chem. Ref. Data, (1998) Monograph 9.

[61] L. Wang, T. Maxisch, G. Ceder, Oxidation energies of transition metal oxides within the GGA+U framework, Phys. Rev. B, 73 (2006) 195107.

[62] J. M. Howe, Interfaces in materials, atomic structure, thermodynamics and kinetics of solid-vapor, solid-liquid and solid-solid interfaces, Wiley, Chichester (1997).

[63] C. Guo, Z. Du, C. Li, A thermodynamic description of the Mg-Pr-Y system, CALPHAD, 32 (2008) 177-187.

[64] W. Gong, D. Li, Z. Chen, F. Zheng, Y. Liu, Y. Du, B. Huang, Phase equilibria of the $\mathrm{TiO}_{2}-\mathrm{Y}_{2} \mathrm{O}_{3}$ system, CALPHAD 33 (2009) 624-627.

[65] L. Zhang, C.-C. Fu, G.-H. Lu. Energetic landscape and diffusion of He in $\alpha$-Fe grain boundaries from first principles, Phys. Rev. B 87 (2013) 134107.

[66] Y. Zhang, W.-Q. Feng, Y.-L. Liu, G.-H. Lu, T. Wang, First-principles study of helium effect in a ferromagnetic iron grain boundary: Energetics, site preference and segregation. Nucl. Instrum. 
Methods. Phys. Res. B 267 (2009) 3200-3203.

[67] L. Zhang, X. Shu, S. Jin, Y. Zhang, G.-H. Lu, First-principles study of He effects in a bec Fe grain boundary: site preference, segregation and theoretical tensile strength, J. Phys.: Condens. Matter $22(2010) 375401$.

[68] L. Zhang, Y. Zhang, G.-H. Lu, Structure and stability of He and He-vacancy clusters at a $\Sigma 5(310) /[001]$ grain boundary in bcc Fe from first-principles, J. Phys.: Condens. Matter 25 (2013) 095001.

[69] A. Caro, J. Hetherly, A. Stukowski, M. Caro, E. Martinez, S. Srivilliputhur, L. Zepeda-Ruiz, M. Nastasi, Properties of Helium bubbles in Fe and FeCr alloys, J. Nucl. Mater. 418 (2011) 261-268.

[70] R. E. Stoller, G. R. Odette, Analytical solutions for helium bubble and critical radius parameters using a hard sphere equation of state, J. Nucl. Mater., 131 (1985) 118-125.

[71] R. Konings, Comprehensive Nuclear Materials, p.141-193, Elsevier (2012). 

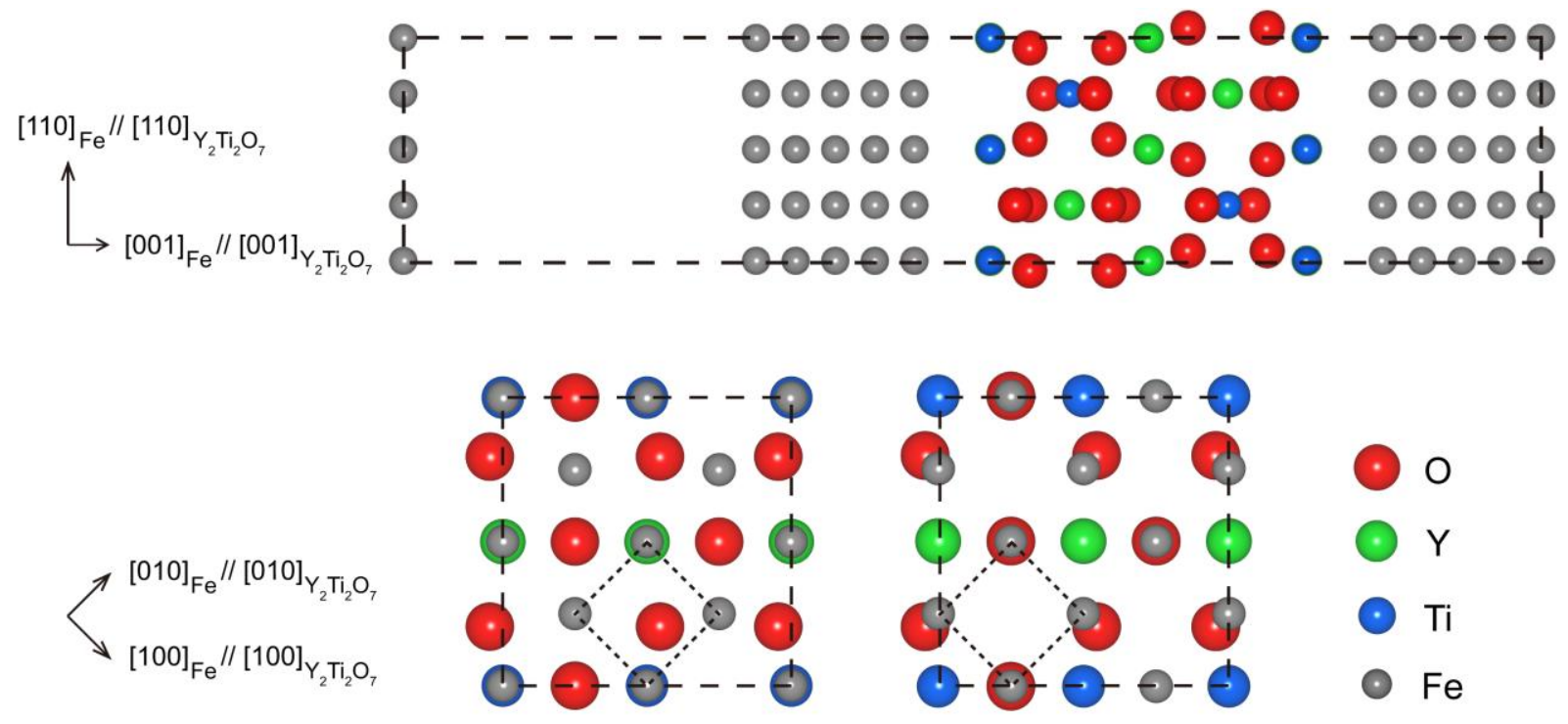

(a) Top

(b) Bridge

Fig. 1 The sandwich supercell for the $\mathrm{Fe}(100)(2 \sqrt{2} \times 2 \sqrt{2}) / \mathrm{Y}_{2} \mathrm{Ti}_{2} \mathrm{O}_{7}(100)(\sqrt{2} / 2 \times \sqrt{2} / 2)$ interface and the two representative coordination types: (a) Y/Ti-top and (b) Y/Ti-bridge. For clarity, we only show the interfacial atoms of $\mathrm{Fe}, \mathrm{Y}$, and Ti in top-views. 


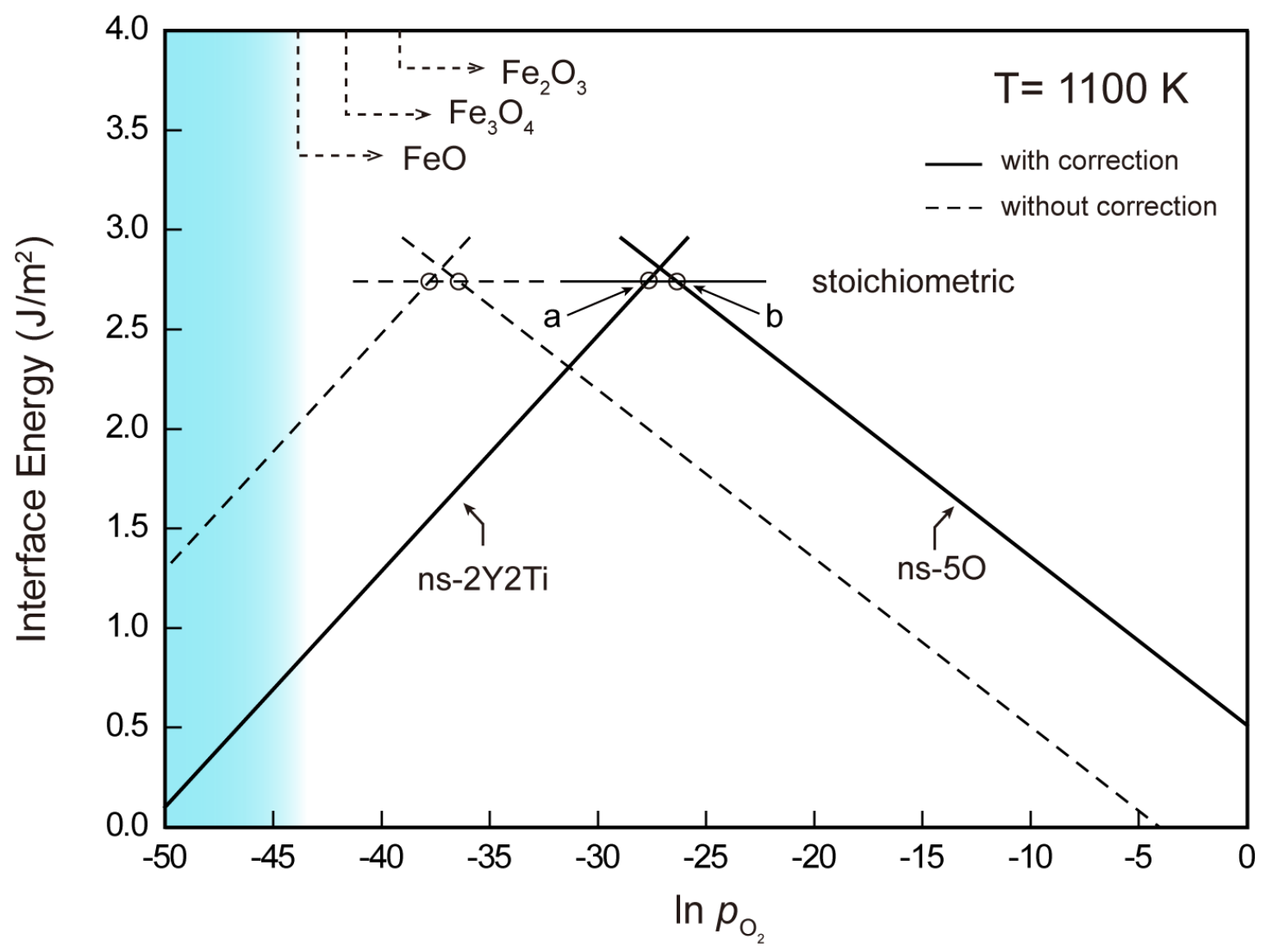

Fig. 2 The calculated isothermal section of the $\mathrm{Fe}(100) / \mathrm{Y}_{2} \mathrm{Ti}_{2} \mathrm{O}_{7}(100)$ interface phase diagram at $T=$ $1100 \mathrm{~K}$. Comparison is made between with and without the temperature correction on oxygen chemical potentials. In either case, the interface is predicted to be Y/Ti-rich in NFAs, typically with a non-stoichiometric 2Y2Ti (ns-2Y2Ti) termination. 


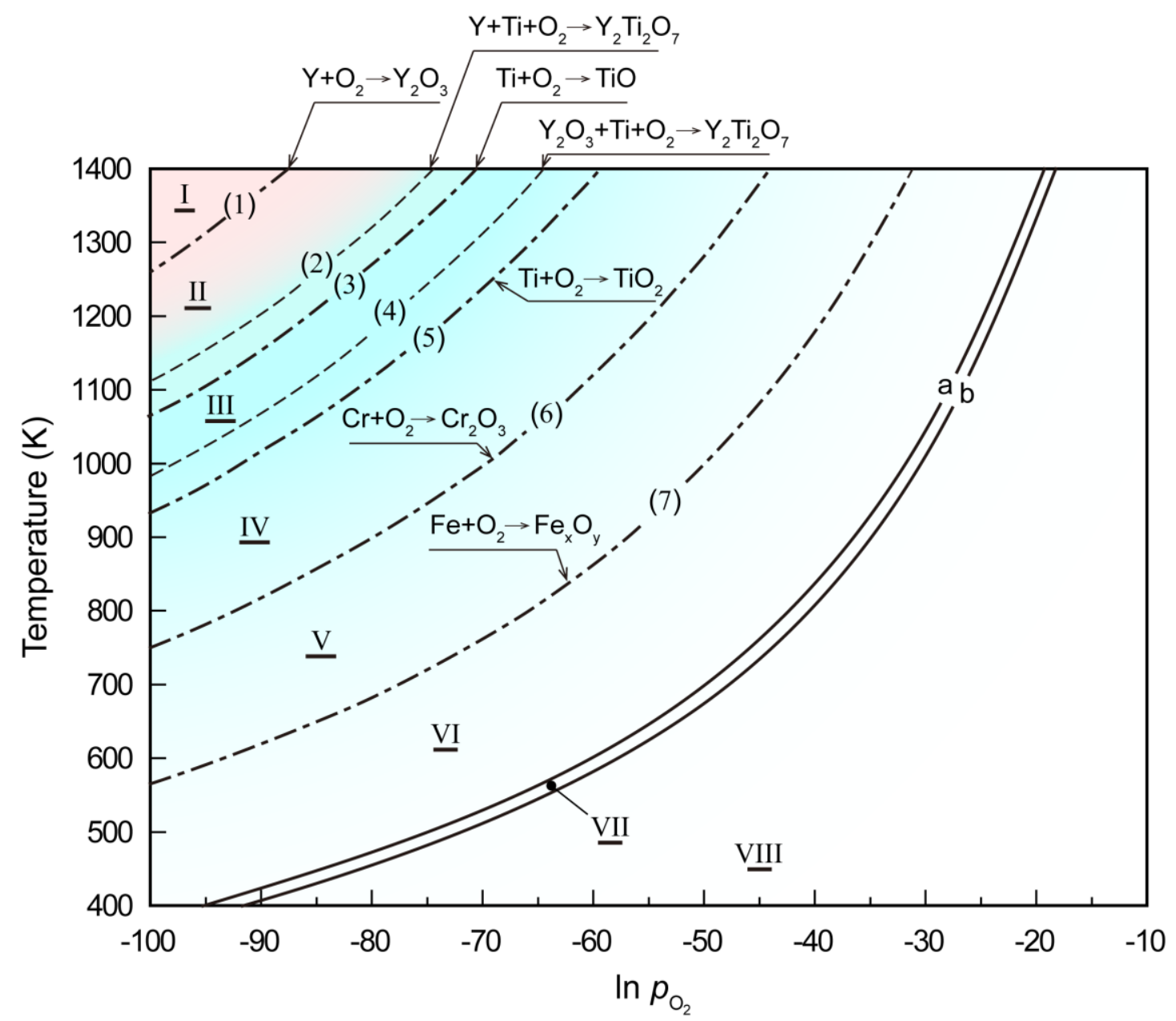

Fig. 3 Calculated phase diagram for in-situ $\mathrm{Y}_{2} \mathrm{Ti}_{2} \mathrm{O}_{7}$ in NFAs. Zone I: single phase $\mathrm{Fe}(\mathrm{Cr} / \mathrm{Y} / \mathrm{Ti} / \mathrm{O})$ with dissolved Y, Ti, Cr, and O, Zone II: double phase region of $\mathrm{Y}_{2} \mathrm{O}_{3}+\mathrm{Fe}(\mathrm{Cr} / \mathrm{Y} / \mathrm{Ti} / \mathrm{O})$, Zone III: multi-phase region of $\mathrm{Y}_{2} \mathrm{Ti}_{2} \mathrm{O}_{7}(\mathrm{Y} / \mathrm{Ti}$-rich $)+\mathrm{Y}_{2} \mathrm{O}_{3}+\mathrm{TiO}+\mathrm{Fe}(\mathrm{Cr} / \mathrm{Ti} / \mathrm{O})$, Zone $\mathrm{IV}$ : multi-phase region of $\mathrm{Y}_{2} \mathrm{Ti}_{2} \mathrm{O}_{7}(\mathrm{Y} / \mathrm{Ti}$-rich $)+\mathrm{Y}_{2} \mathrm{O}_{3}+\mathrm{TiO} / \mathrm{TiO}_{2}+\mathrm{Fe}(\mathrm{Cr} / \mathrm{O})$, Zone V: $\mathrm{Y}_{2} \mathrm{Ti}_{2} \mathrm{O}_{7}(\mathrm{Y} / \mathrm{Ti}$-rich $)+\mathrm{Y}_{2} \mathrm{O}_{3}+\mathrm{TiO} / \mathrm{TiO}_{2}+\mathrm{Cr}_{2} \mathrm{O}_{3}$ $+\mathrm{Fe}(\mathrm{O})$, Zone VI: $\mathrm{Y}_{2} \mathrm{Ti}_{2} \mathrm{O}_{7}(\mathrm{Y} / \mathrm{Ti}-$ rich $)+\mathrm{Y}_{2} \mathrm{O}_{3}+\mathrm{TiO} / \mathrm{TiO}_{2}+\mathrm{Cr}_{2} \mathrm{O}_{3}+\mathrm{Fe}_{\mathrm{x}} \mathrm{O}_{\mathrm{y}}$, Zone VII: $\mathrm{Y}_{2} \mathrm{Ti}_{2} \mathrm{O}_{7}($ stoi $)+\mathrm{Y}_{2} \mathrm{O}_{3}$ $+\mathrm{TiO} / \mathrm{TiO}_{2}+\mathrm{Cr}_{2} \mathrm{O}_{3}+\mathrm{Fe}_{\mathrm{x}} \mathrm{O}_{\mathrm{y}}$, Zone VIII: $\mathrm{Y}_{2} \mathrm{Ti}_{2} \mathrm{O}_{7}(\mathrm{O}-$ rich $)+\mathrm{Y}_{2} \mathrm{O}_{3}+\mathrm{TiO} / \mathrm{TiO}_{2}+\mathrm{Cr}_{2} \mathrm{O}_{3}+\mathrm{Fe}_{\mathrm{x}} \mathrm{O}_{\mathrm{y}}$. 


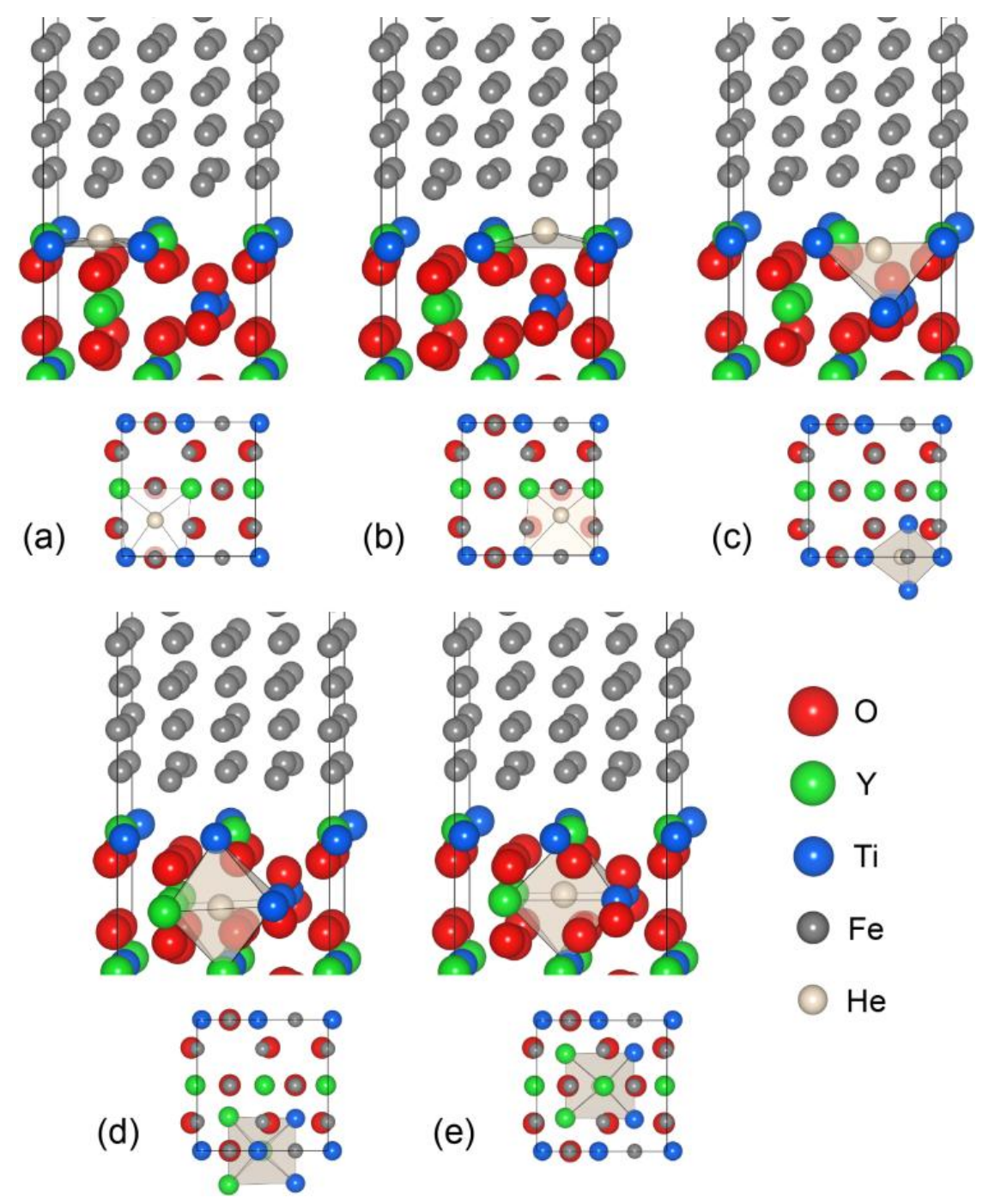

Fig. 4 Possible interstitial sites for helium on the Y/Ti-rich interface: (a) $\mathrm{He}_{\mathrm{A}}^{\mathrm{i}}$, (b) $\mathrm{He}_{\mathrm{B}}^{\mathrm{i}}$, (c) $\mathrm{He}_{\mathrm{T}}^{\mathrm{i}}$, (d) $\mathrm{He}_{\mathrm{A}}^{\mathrm{s}}$, and (e) $\mathrm{He}_{\mathrm{B}}^{\mathrm{s}}$. Corresponding top views of interfacial layers are shown at the bottom. 

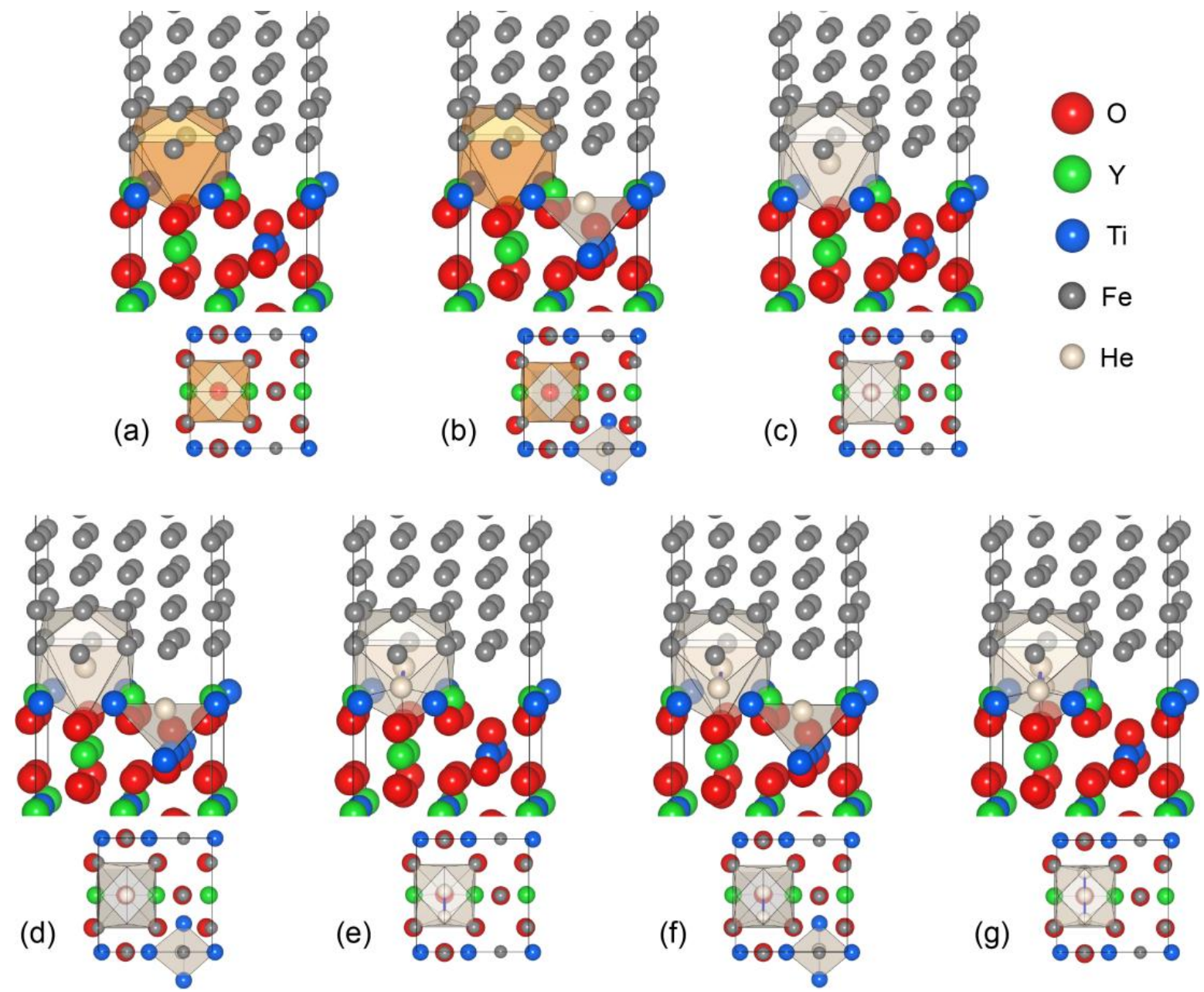

Fig. 5 Possible configurations of helium-vacancy clusters on the Y/Ti-rich interface: (a) $\mathrm{V}^{\mathrm{i}}$, (b) $\mathrm{He}^{\mathrm{i}}{ }_{\mathrm{T}}+\mathrm{V}^{\mathrm{i}}$,

(c) $\mathrm{He}_{\mathrm{V}}^{\mathrm{i}}$, (d) $\mathrm{He}_{\mathrm{V}}^{\mathrm{i}}+\mathrm{He}_{\mathrm{T}}^{\mathrm{i}}$, (e) $(2 \mathrm{He})_{\mathrm{V}}^{\mathrm{i}}$, (f) $(2 \mathrm{He})_{\mathrm{V}}^{\mathrm{i}}+\mathrm{He}_{\mathrm{T}}^{\mathrm{i}}$, and (g) $(3 \mathrm{He})_{\mathrm{V}}^{\mathrm{i}}$. Corresponding top views of interfacial layers are shown at the bottom. 


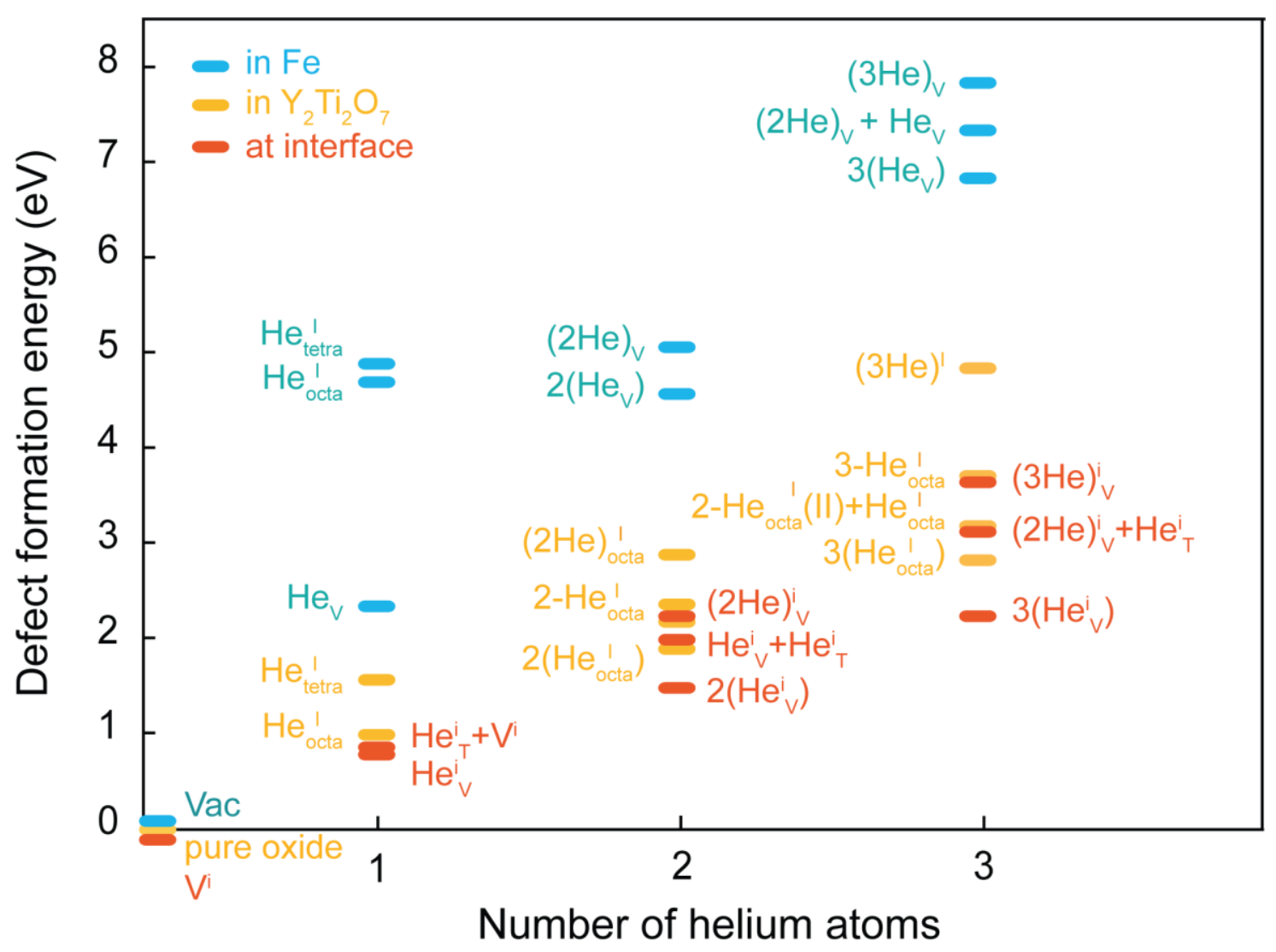

Fig. 6 Formation energies of helium-vacancy clusters on the interface compared to those in iron and in the oxide bulk as reported in Ref. [32]. 


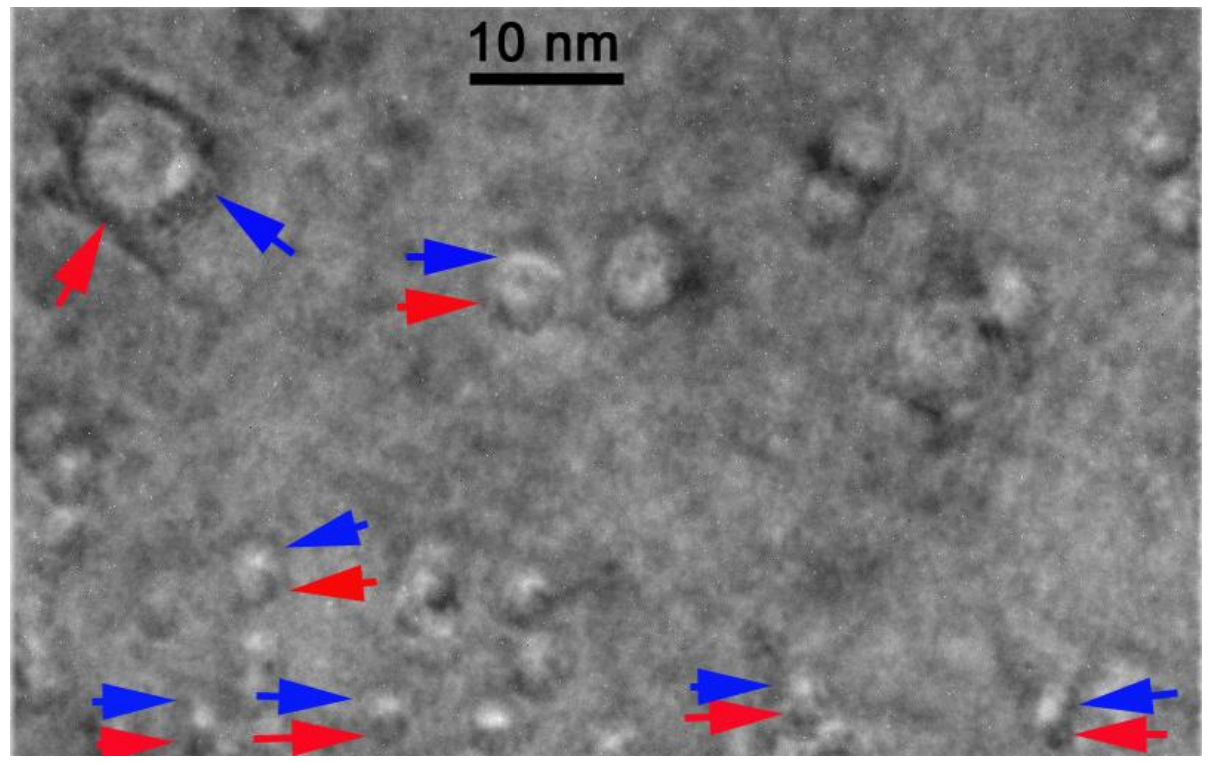

Fig. 7 The high degree of helium bubble and nano-oxide association in a 14YWT NFA dual ion irradiated at $650^{\circ} \mathrm{C}$ to 48 displacements per atom and 2200 appm helium, with some examples highlighted by the blue and red arrows, indicating the bubbles and nano-oxides respectively. 

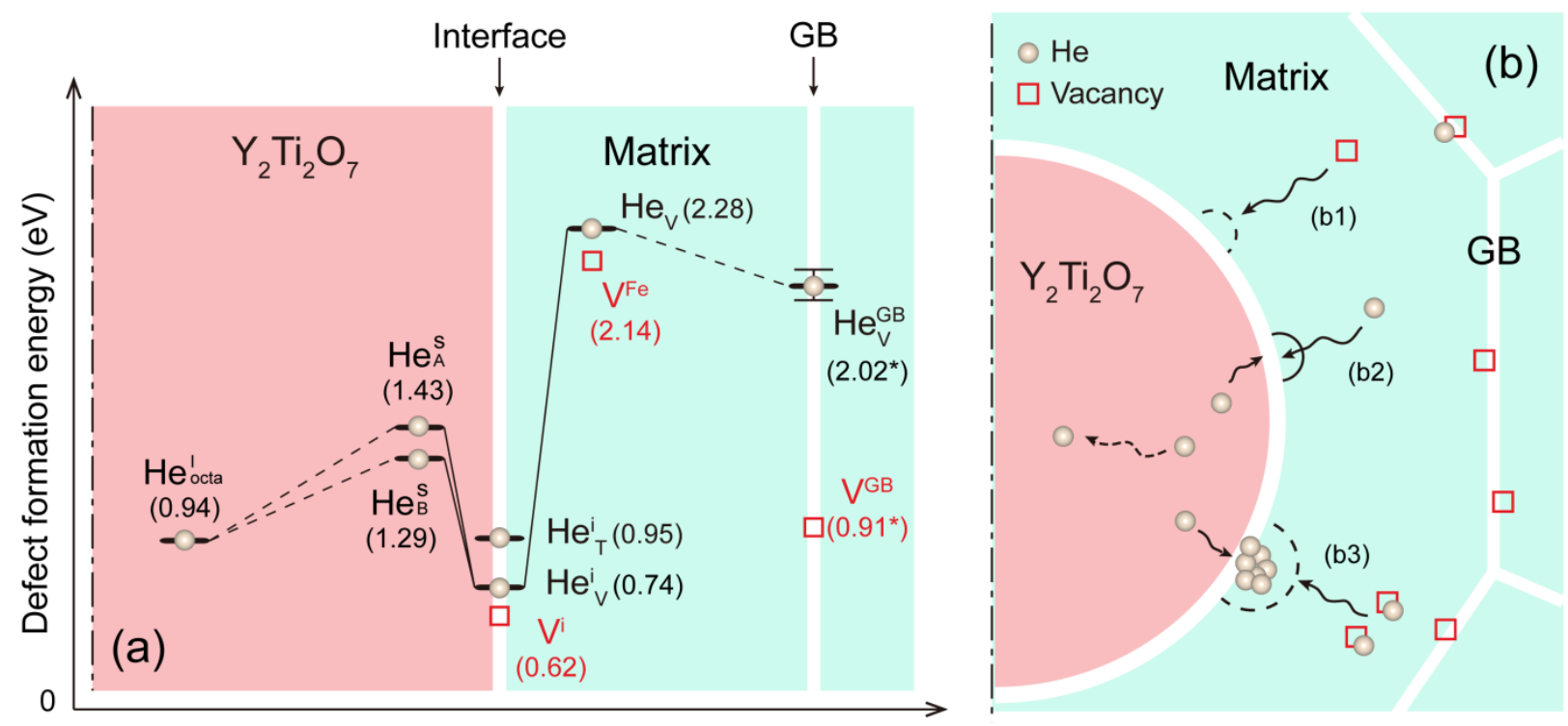

Fig. 8 (a) Energies of forming vacancies and trapping helium at different locations in NFAs. Locations include the ferrite matrix, the bulk oxides, the oxide interfaces, and the iron grain boundaries. (b) The schematic formation of interfacial helium bubbles in NFAs. The superscript ' $*$ ' refers to the DFT results available in the literature. 
Table 1 Calculated formation energies of various helium-trapped interface structures

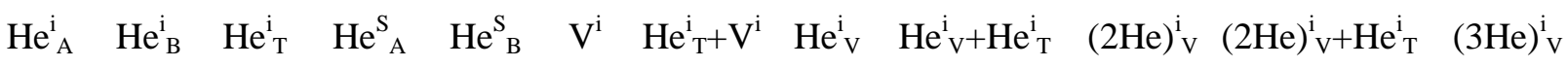

\begin{tabular}{ccccccccccccc}
\hline$E_{f}$ & 1.32 & 1.20 & 0.95 & 1.43 & 1.29 & 0.62 & 1.42 & 1.36 & 2.61 & 2.83 & 3.73 & 4.22 \\
$(\mathrm{eV})$ & & & & & & & \\
\hline
\end{tabular}




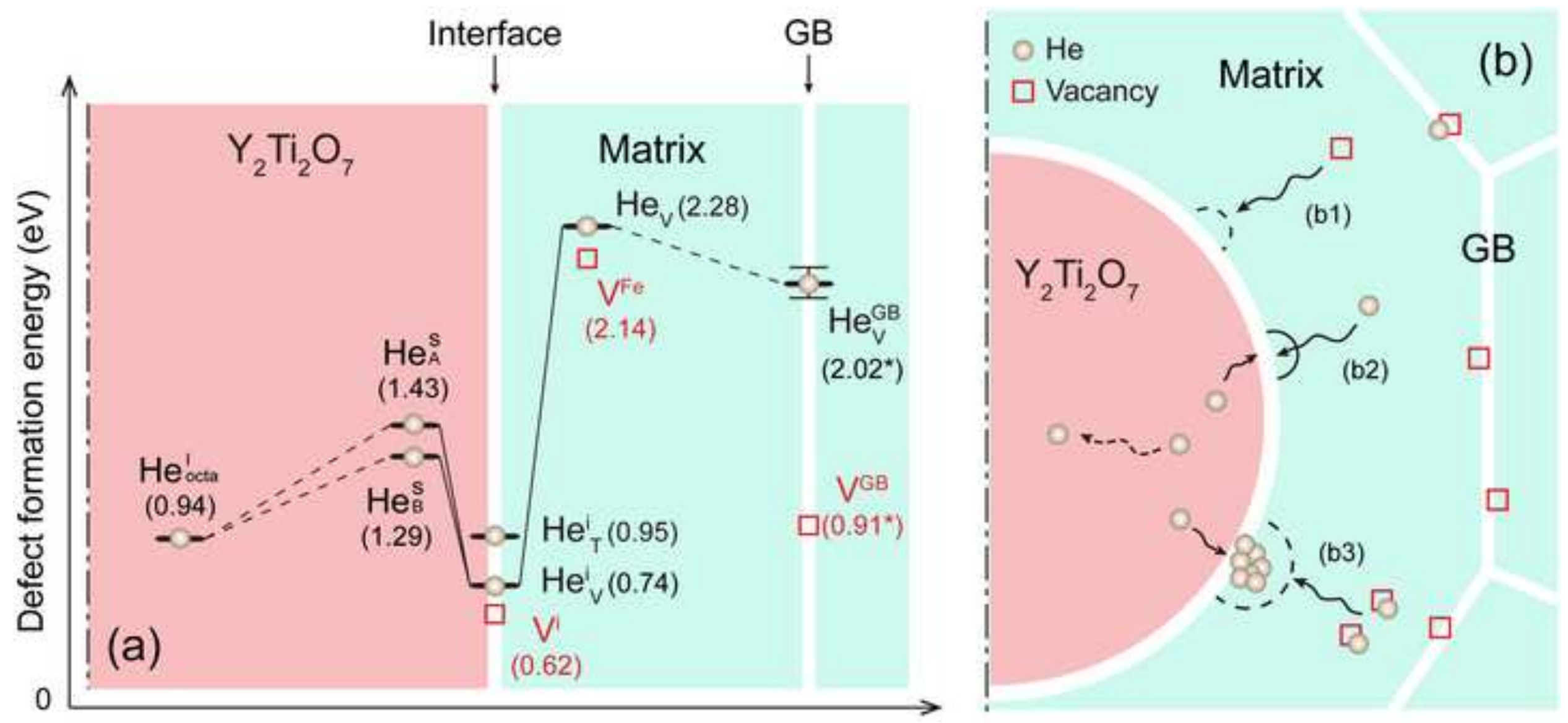

